Article

\title{
Cobalt-iron Oxide, Alloy and Nitride: Synthesis, Characterization and Application in Catalytic Peroxymonosulfate Activation for Orange II Degradation
}

\author{
Kaixin Zhu ${ }^{1,2}$, Changzi Jin ${ }^{1}$, Zoltán Klencsár ${ }^{3}$, Ayyakannu Sundaram Ganeshraja ${ }^{1}$ \\ and Junhu Wang ${ }^{1, *}$ \\ 1 Mössbauer Effect Data Center, Dalian Institute of Chemical Physics, Chinese Academy of Sciences, \\ Dalian 116023, China; zhukx12@dicp.ac.cn (K.Z.); jinchangzi@dicp.ac.cn (C.J.); \\ ganeshraja@dicp.ac.cn (A.S.G.) \\ 2 University of Chinese Academy of Sciences, Beijing 100049, China \\ 3 Nuclear Analysis and Radiography Department, Institute for Energy Security and Environmental Safety, \\ Centre for Energy Research, Hungarian Academy of Sciences, Konkoly Thege Miklós út 29-33, \\ 1121 Budapest, Hungary; klencsar.zoltan@energia.mta.hu \\ * Correspondence: wangjh@dicp.ac.cn; Tel.: +86-411-8437-9159
}

Academic Editors: Shaobin Wang and Xiaoguang Duan

Received: 27 February 2017; Accepted: 24 April 2017; Published: 4 May 2017

\begin{abstract}
In meeting the need for environmental remediation in wastewater treatment and the development of popular sulfate-radical-based advanced oxidation processes (SR-AOPs), a series of $\mathrm{Co} / \mathrm{Fe}$-based catalysts with confirmed phase structure were prepared through extended soft chemical solution processes followed by atmosphere-dependent calcination. Powder X-ray diffraction (XRD), scanning electron microscopy (SEM), transmission electron microscopy (TEM), X-ray photoelectron spectroscopy (XPS) and ${ }^{57} \mathrm{Fe}$ Mössbauer spectroscopy were employed to characterize the composition, morphology, crystal structure and chemical state of the prepared catalysts. It was shown that calcination in air, nitrogen and ammonia atmospheres generated Co-Fe catalysts with cobalt ferrite $\left(\mathrm{CoFe}_{2} \mathrm{O}_{4}\right), \mathrm{Co}-\mathrm{Fe}$ alloy and Co-Fe nitride as dominant phases, respectively. The prepared $\mathrm{Co} / \mathrm{Fe}$-based catalysts were demonstrated to be highly efficient in activating peroxymonosulfate (PMS) for organic Orange II degradation. The activation efficiency of the different catalysts was found to increase in the order $\mathrm{CoFe}_{2} \mathrm{O}_{4}<\mathrm{Co}$-Fe nitride $<\mathrm{Co}-\mathrm{Fe}$ alloy. Sulfate radical was found to be the primary active intermediate species contributing to the dye degradation for all the participating catalysts. Furthermore, a possible reaction mechanism was proposed for each of the studied catalysts. This study achieves progress in efficient cobalt-iron catalysts using in the field of SR-AOPs, with potential applications in environment remediation.
\end{abstract}

Keywords: Co-Fe catalysts; advanced oxidation processes; peroxymonosulfate activation; sulfate radical

\section{Introduction}

Industries such as textiles, printing, plastics, pharmaceuticals, rubber, etc., may bring great threats to the water environment, owing to the production of lots of organic pollutants, most of which are carcinogenic, teratogenic, mutagenic and resistant to biodegradation [1]. Thus, advanced oxidation processes (AOPs) have been developed to solve the wastewater issues, which have been attractive techniques for the realization of powerful degradation ability. As classic active species, hydroxyl radical $(\cdot \mathrm{OH})$ generated during the oxidation processes has been widely investigated because of its remarkable 
reactivity towards almost all the organic compounds [2]. However, it may suffer from limitations such as $\mathrm{pH}$ value dependence, slow reaction rate, sludge generation and difficulties regarding the safety of storage and transportation of the oxidant-hydrogen peroxide $\left(\mathrm{H}_{2} \mathrm{O}_{2}\right)$. Recently, on account of their superior oxidation ability, good safety, wide range of $\mathrm{pH}$ conditions, sulfate-radical-based advanced oxidation processes (SR-AOPs) have emerged as a promising technique and a favorable alternative to $\mathrm{H}_{2} \mathrm{O}_{2}$ based organics degradation processes [3].

With respect to other transition-metal-based catalysts, cobalt ions and their composites were reported to be more efficient as peroxymonosulfate (PMS) activators in most organic pollutant degradations [4]. Since the first report about $\mathrm{Co}^{2+}$ catalytic decomposition of PMS, homogeneous processes on different $\mathrm{Co}^{2+}$ counteranions [5], such as nitrate, sulfate, chloride and acetate, and heterogeneous processes on cobalt oxides and supported composites [6-8], have been explored in succession. Subsequently, metal-free carbocatalysis [9-13]—studied mainly by Wang and Sun's group-attracted great attention compared to metal heterogeneous catalysts. Even though other transition metals ( $\mathrm{Mn}, \mathrm{Cu}, \mathrm{Zn}, \mathrm{Ni}$ etc.) [14] were also effective in PMS activation, the cobalt system with no need for activity-enhancing assistance (such as microwave, UV, visible light, thermal activation, etc.) was the most popular choice for investigation. Iron possesses the advantages of low cost, rich supplies and environmental friendliness, so it has been widely applied in water remediation. The addition of Fe into the cobalt compound can not only enhance the reactivity of PMS activation through enriching hydroxyl groups on the surface, but also endow the catalyst with easier separation and recovery properties due to its magnetism, as well as suppressing cobalt leaching owing to the strong Co-Fe interactions [15]. Hu et al. prepared the catalyst by one-step incipient wetness impregnation and put forward that in comparison with Co/SBA-15, CoFe/SBA-15 maintained higher catalytic activity and better stability, and its recovery was also more easily accomplished. Iron-cobalt oxide catalysts coupled with PMS have been reported to be efficient in organics degradation [16]. More recently, octahedral $\mathrm{CoFe} / \mathrm{CoFe}_{2} \mathrm{O}_{4}$ was synthesized using a one-pot hydrothermal method and displayed excellent PMS activity [17]. Different series of Co-Fe oxides were prepared by thermal oxidation [15], sol-gel [18], co-precipitation [19,20], hydrothermal [21] and precipitation-oxidation [22] methods, with their application areas including PMS activated pollutant degradation and adsorption processes.

Previously, our group synthesized $\mathrm{TiO}_{2}$ and metal-doped $\mathrm{TiO}_{2}$ through a soft chemical solution process, which exhibited good photocatalytic activity in Methylene Blue (MB) degradation [23-25]. Afterwards, zinc ferrite was obtained through the same method and showed good photo-Fenton-like activity in Orange II degradation by PMS activation under visible light irradiation [26]. With the aim of avoiding the energy-consuming usage of visible light, we set out to fabricate a highly active cobalt-iron catalyst through such a soft chemical solution process. In the frame of this study, for the first time, a series of cobalt-iron catalysts including $\mathrm{CoFe}_{2} \mathrm{O}_{4}$ spinel, $\mathrm{Co}-\mathrm{Fe}$ alloy and $\mathrm{Co}$-Fe nitride, were prepared through soft chemical solution method followed by calcination under different atmospheres (air, $\mathrm{N}_{2}$ and $\mathrm{NH}_{3}$ ). The catalytic performances of the corresponding catalysts were investigated in PMS catalytic activation for Orange II degradation, which displayed high efficiency in organics treatments. Most importantly, Co-Fe nitride was found to have good activity and excellent stability in catalytic activation of PMS for dye degradation for the first time.

\section{Results and Discussion}

\subsection{Basic Characterization of Cobalt-Iron Catalysts}

The crystalline structures of the synthesized cobalt-iron catalysts were determined by XRD technique. Based on the XRD patterns (Figure 1), all the diffraction peaks of CFA-500 (referring to cobalt-iron catalyst calcined under air at $500^{\circ} \mathrm{C}$ ) and CFA-600 (referring to cobalt-iron catalyst calcined under air at $600{ }^{\circ} \mathrm{C}$ ) can be attributed to $\mathrm{CoFe}_{2} \mathrm{O}_{4}$ spinel ferrite (JCPDS 00-022-1086). For the CFN samples (referring to cobalt-iron catalysts calcined under $\mathrm{N}_{2}$ ), distinct peaks at $2 \theta$ values of $44.8^{\circ}(110)$ and $65.3^{\circ}$ (200) can be indexed to Co-Fe alloy (Wairauite, JCPDS 00-044-1433). When calcined under 
ammonia, the main diffraction peaks at $37.5,40.9,42.9,56.7,67.7$ and $75.9^{\circ}$ were assigned to Co-Fe nitride (having a crystal structure analogous to that of $\mathrm{Fe}_{2} \mathrm{~N}$, JCPDS 01-072-2126) for CFNH-600 (referring to cobalt-iron catalyst calcined under ammonia at $600{ }^{\circ} \mathrm{C}$ ). But CFNH-500 (referring to cobalt-iron catalyst calcined under ammonia at $500{ }^{\circ} \mathrm{C}$ ) calcined at lower temperature still contained alloy beside the main nitride phase (having similar crystal structure to that of $\mathrm{FeN}_{0.09}$, JCPDS 01-075-2140) with low N content. Higher temperature promoted the formation of nitride phase. In addition, it was found that with the increase of the calcination temperature, the intensity of the diffraction peaks increased, indicating better crystallinity and larger particle size. According to the Scherrer equation, the grain size is 13.0, 41.7, 35.8 and $47.7 \mathrm{~nm}$ for CFA-500, CFA-600, CFN-500 (referring to cobalt-iron catalyst calcined under $\mathrm{N}_{2}$ at $500{ }^{\circ} \mathrm{C}$ ), and CFN-600 (referring to cobalt-iron catalyst calcined under $\mathrm{N}_{2}$ at $600{ }^{\circ} \mathrm{C}$ ), respectively. The nitride grain size is about $18.2 \mathrm{~nm}$ in the CFNH-500 sample while the Co-Fe alloy has grain size of about $30 \mathrm{~nm}$. The main nitride phase of CFNH-600 gives grain size of $24 \mathrm{~nm}$ calculated from its (011) crystal plane. It can be deduced that the crystal structure of the prepared cobalt-iron catalysts mainly depends on the calcination atmosphere. Phase-pure samples of cobalt-iron oxide, alloy and nitride were obtained by calcination at $600{ }^{\circ} \mathrm{C}$, which were chosen as catalysts for performance evaluation as discussed below.

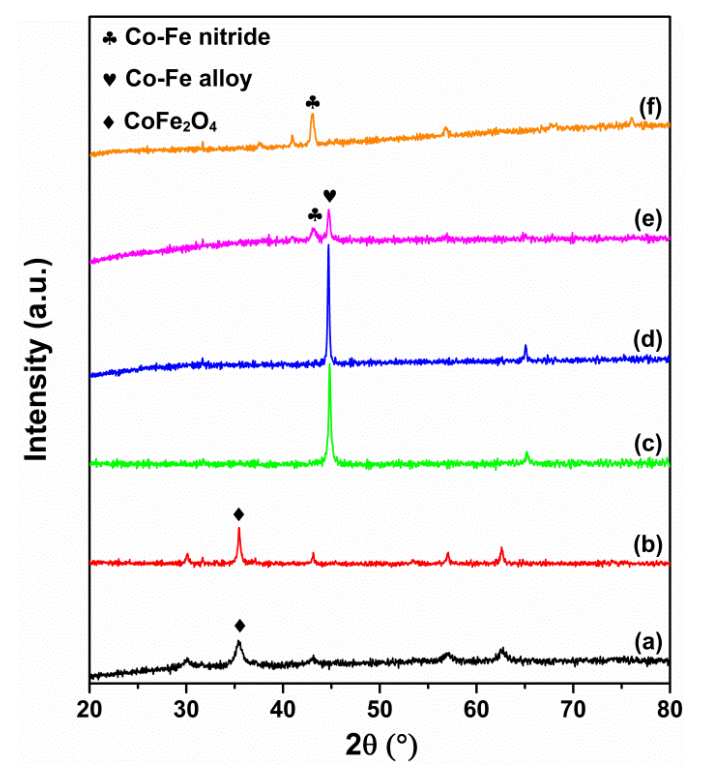

Figure 1. XRD patterns of cobalt-iron catalysts prepared under different calcination atmospheres and temperatures (a) CFA-500; (b) CFA-600; (c) CFN-500; (d) CFN-600; (e) CFNH-500 and (f) CFNH-600.

The morphologies presented by SEM for the prepared Co/Fe-based catalysts are shown in Figure 2. Obviously, the air-calcined sample of CFA-500 exhibited sphere-like nanoparticles with the size of 10-20 nm (Figure 2a), which was consistent with the XRD results. Increasing the calcination temperature led to particle aggregation (Figure $2 b$ ). When the calcination was conducted in a nitrogen atmosphere, the resultant CFN samples exhibited bright, highly dispersed sphere-like nanoparticles representing the Co-Fe alloys, along with some petal-like layers on the surface (Figure 2c,d). According to the element analysis, the distinctive morphology on the surface of CFN-500 and CFN-600 could be attributed to the formation of cobalt-iron oxide resulting from the slight surface oxidation during the passivation process, which is consistent with the Mössbauer results below. With the increase of calcination temperature, the particles tended to grow larger. Relatively large nanoparticles with irregular shape can be found in CFNH-500 (Figure 2e), while an increase of the calcination temperature up to $600{ }^{\circ} \mathrm{C}$ resulted in a clearly different morphology. Namely, in the latter case, severe sintering took place accompanied by formation of little porous structure (Figure 2f). It is worth mentioning that $\mathrm{N}$ was successfully introduced into the samples during the calcination process, with its concentration 
increasing from $23 \%$ to $34 \%$ with the increase of temperature according to the energy spectrum analysis results. Correspondingly, the relative contents of $\mathrm{Co}$ and Fe increased but those of $\mathrm{C}$ and $\mathrm{O}$ decreased with increasing temperature. The SEM images demonstrated that different kinds of morphologies were developed under different calcination atmospheres.

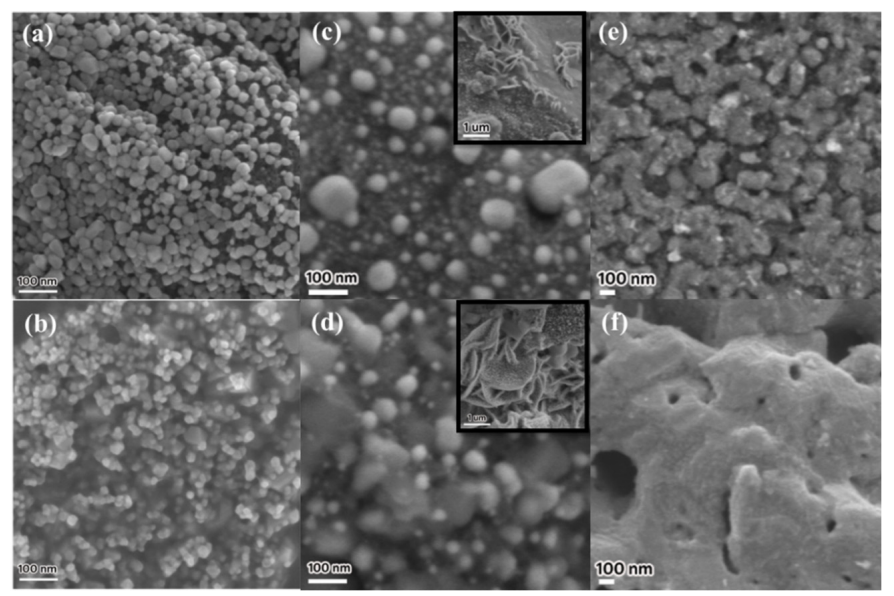

Figure 2. SEM images of cobalt-iron catalysts prepared under different calcination atmospheres and temperatures (a) CFA-500; (b) CFA-600; (c) CFN-500; (d) CFN-600; (e) CFNH-500 and (f) CFNH-600.

TEM images of the obtained samples are presented in Figure 3. The particle size characteristic of CFA-500 was $\sim 10 \mathrm{~nm}$ (Figure 3a), and about $40 \mathrm{~nm}$ for CFA-600 (Figure 3b) showing that the higher calcination temperature promoted the formation of larger particles, in agreement with corresponding SEM and XRD results. Nevertheless, metal particles dispersed on carbon support were obtained by $\mathrm{N}_{2}$ calcination (Figure 3c,d). Carbon in CFN samples is generated from the carbonization of organic species present in reactants during calcination under nitrogen. One can discern that many dark-colored nanoparticles (metal species) were dispersed in the light-colored matrix, which was ascribed to carbon species formed during the carbonization process. The nanoparticles grew larger, even to $50 \mathrm{~nm}$, when the calcination temperature was increased from 500 to $600{ }^{\circ} \mathrm{C}$. As for the CFNH-500, non-uniform nanoparticles were observed, interestingly, with the appearance of a core-shell structure (Figure 3e). However, irregular morphology was present on the Co-Fe nitride (Figure 3f). It is clear that higher calcination temperature leads to severe particle aggregation and larger particle sizes.

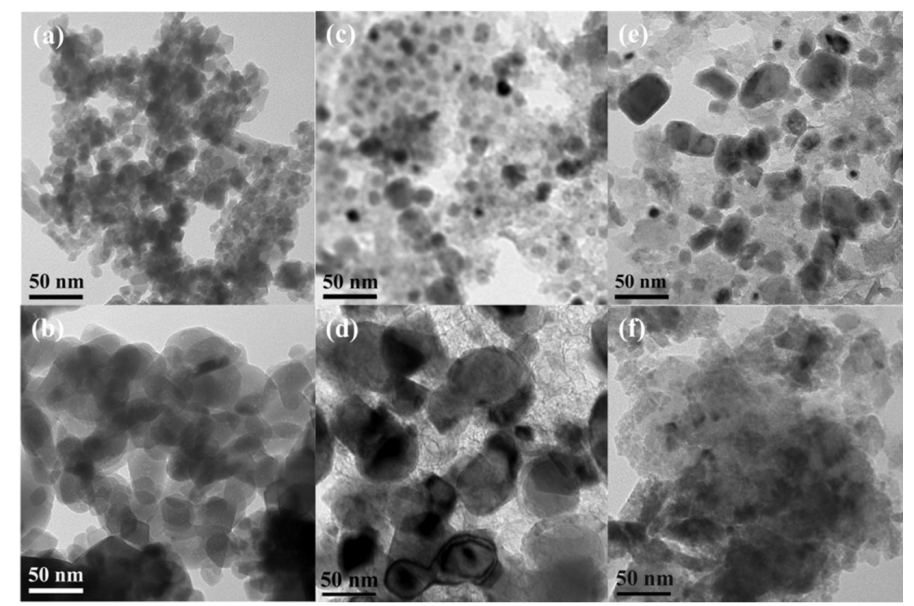

Figure 3. TEM images of cobalt-iron catalysts prepared under different calcination atmospheres and temperatures (a) CFA-500; (b) CFA-600; (c) CFN-500; (d) CFN-600; (e) CFNH-500 and (f) CFNH-600. 
Figure 4 displays the $\mathrm{N}_{2}$ adsorption-desorption isotherms and corresponding pore size distribution of the prepared $\mathrm{Co} / \mathrm{Fe}-$ based catalysts. Corresponding textural parameters are displayed in Table S1. Except CFNH-600, other samples give isotherms with hysteresis loops at relatively high pressures of 0.4-1.0, which indicates the existence of mesopores generated due to the accumulation of nanoparticles. This is confirmed by the calculated pore size distribution that exhibits mesopores (mainly in the range of $2-40 \mathrm{~nm}$ ), and some macropores $(>50 \mathrm{~nm}$ ) as well. The absence of accumulation pores in CFNH-600 can be attributed to its bulk particles, which were generated via aggregation during calcination. The large particle size of CFNH-600 also leads to its lower BET surface area $\left(13.0 \mathrm{~m}^{2} \mathrm{~g}^{-1}\right)$ and pore volume $\left(0.019 \mathrm{~cm}^{3} \mathrm{~g}^{-1}\right)$ relative to other samples. Regardless of the calcination atmosphere, with the increase of calcination temperature, the BET specific surface area and pore volume decrease markedly for all the samples, which is another consequence of the particle aggregation, in accordance with SEM and TEM results. The large surface area of the $\mathrm{N}_{2}$-calcined samples, especially for CFN-500, is mainly due to the existence of carbon in samples.
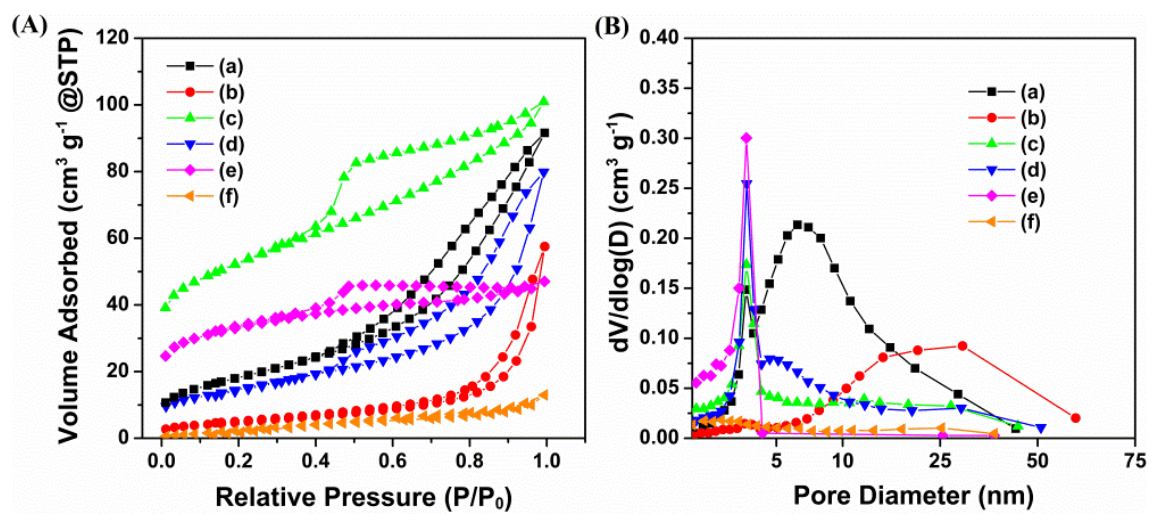

Figure 4. $\mathrm{N}_{2}$ adsorption-desorption isotherms (A) and pore size distributions (B) of cobalt-iron catalysts (a) CFA-500; (b) CFA-600; (c) CFN-500; (d) CFN-600; (e) CFNH-500 and (f) CFNH-600.

\section{2. ${ }^{57}$ Fe Mössbauer Spectroscopy Characterization}

Mössbauer spectroscopy is an excellent tool for examining the local environment of Fe in cobalt-iron catalysts. Room temperature ${ }^{57} \mathrm{Fe}$ Mössbauer spectra of the six samples are shown in Figure $5 a-f$, together with their fit. In the case of CFA-500 and CFA-600, the spectra (Figure 5a,b) mainly reflect the presence of $\mathrm{Fe}^{3+}$ in the $\mathrm{CoFe}_{2} \mathrm{O}_{4}$ spinel phase with a partial degree of inversion. $\mathrm{CoFe}_{2} \mathrm{O}_{4}$ is known to prefer a partially inverse spinel structure where majority of the A (tetrahedral) site is taken by $\mathrm{Fe}^{3+}[27,28]$. We can observe three components corresponding to $\mathrm{Fe}^{3+}$ in tetrahedral (A) site (sextet), octahedral (B) site (sextet with broad peaks reflecting binomial distribution of cobalt atoms at the tetrahedral site) and the smallest particles with superparamagnetic nature (quadrupole doublet). There is a more complete level of inversion (i.e., a lower concentration of Co at tetrahedral sites) present in the sample CFA-600, than in CFA-500, which is presumably connected to the higher calcination temperature applied in the former case. A less intense $\mathrm{Fe}^{3+}$ doublet component, accounting for less than $1 \%$ of the spectral area, may also be present in the spectra (Table S2). Its contribution is smaller in the case of CFA-600, suggesting that higher calcination temperature and/or higher particle size tends to diminish its presence.

In case of samples CFN-500 and CFN-600, the spectra (Figure 5c,d) indicate the presence of the bcc $\mathrm{Fe}_{\mathrm{x}} \mathrm{Co}_{1-\mathrm{x}}$ alloy phase with an Fe:Co ratio that is close to 2:1 in both cases (The fit of the corresponding component was carried out as described in the previous work [29]). A heavily broadened spectral component can be seen in CFN-500 as being associated with the smallest Co-Fe alloy particles that undergo magnetic relaxation on a time scale which is comparable to the Larmor precession time of the ${ }^{57} \mathrm{Fe}$ nucleus. This component is missing from the spectrum of CFN-600 (Figure 5d), in agreement with the larger characteristic particle size of the latter sample. A paramagnetic $\mathrm{Fe}^{3+}$ doublet component can 
also be detected in the spectrum of these samples, with a considerably smaller relative spectral area for CFN-600 ( 2\%) than for CFN-500 ( 7\%) (Table S3), suggesting that this amount can be reduced by increasing the calcination temperature.
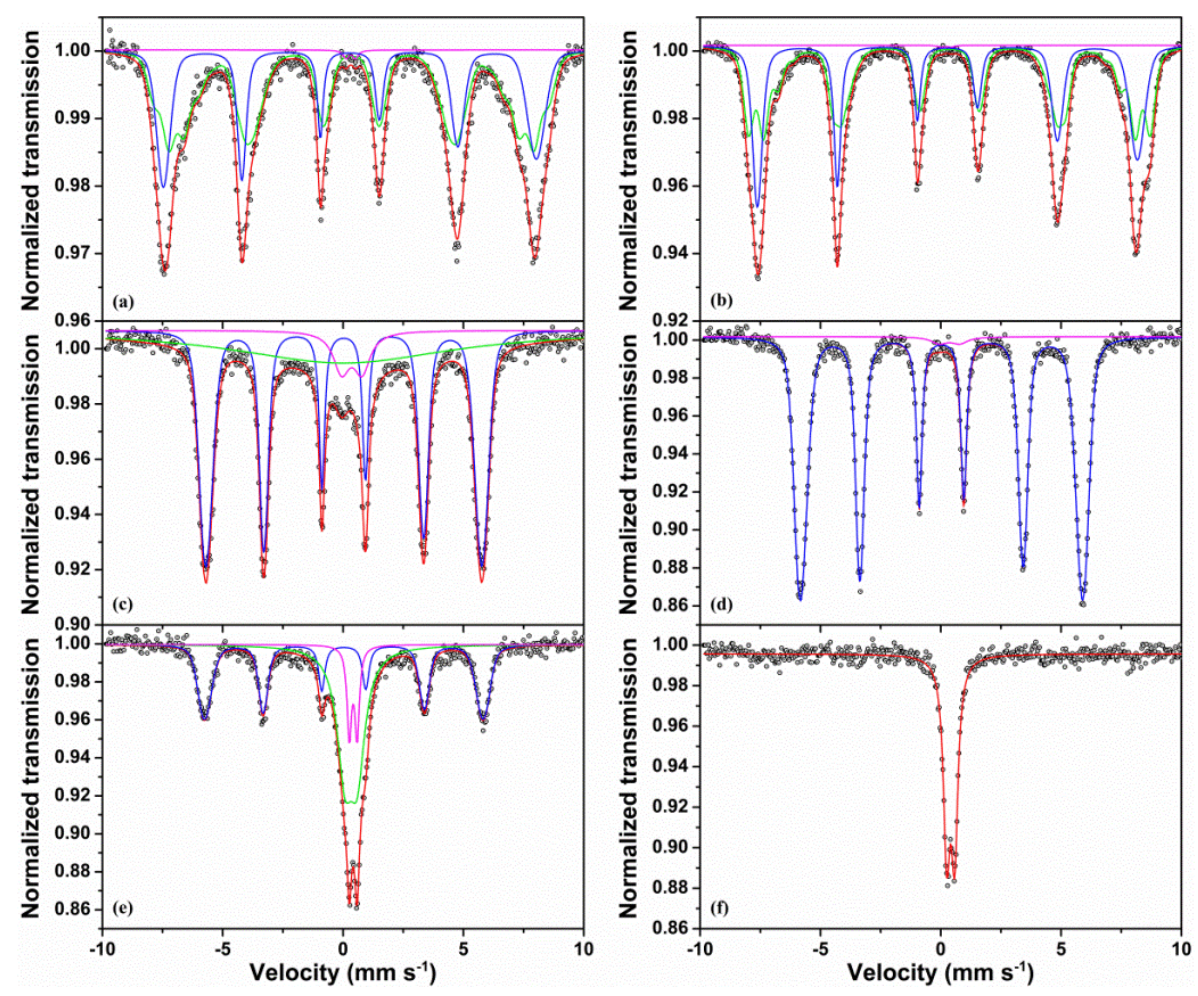

Figure 5. ${ }^{57} \mathrm{Fe}$ Mössbauer spectra of cobalt-iron catalysts prepared under different calcination atmospheres and temperatures (a) CFA-500; (b) CFA-600; (c) CFN-500; (d) CFN-600; (e) CFNH-500 and (f) CFNH-600.

In the sample that was calcined at $500{ }^{\circ} \mathrm{C}$ under $\mathrm{NH}_{3}$ atmosphere, one can detect both $\mathrm{Co}-\mathrm{Fe}$ alloy (magnetic sextet component) and Co-Fe nitride (paramagnetic doublet components) (Figure 5e, Table S4). In contrast, only one paramagnetic iron doublet is observed (Figure 5f) when the calcination was carried out at $600{ }^{\circ} \mathrm{C}$ : the Mössbauer parameters of the doublet are similar to those of $\mathrm{Fe}_{2} \mathrm{~N}$ [30], which is consistent with the XRD results.

\subsection{Surface Elements Analysis}

XPS measurements were carried out on the cobalt-iron samples to investigate the surface characteristics. Full XPS survey in Figure 6a shows the compositional information of the sample CFA-600, indicating the presence of $\mathrm{Co}, \mathrm{Fe}, \mathrm{O}$, as well as $\mathrm{C}$. The high-resolution XPS spectra of $\mathrm{Co} 2 \mathrm{p}$, $\mathrm{Fe} 2 \mathrm{p}$ and $\mathrm{O} 1 \mathrm{~s}$ are shown in Figure $6 \mathrm{~b}-\mathrm{d}$, respectively. The $\mathrm{Co} 2 \mathrm{p}_{3 / 2}$ peaks at $779.5 \mathrm{eV}$ and $781.5 \mathrm{eV}$ were ascribed to $\mathrm{Co}^{2+}$ at octahedral (B) and tetrahedral (A) sites of the spinel structure, respectively, with a satellite peak of $\mathrm{Co} 2 \mathrm{p}_{3 / 2}$ at $\sim 785.5 \mathrm{eV}$ [31]. There were also two peak signals for Fe $2 \mathrm{p}_{3 / 2}$ at 710.0 and $712.7 \mathrm{eV}$, suggesting the occupation of octahedral and tetrahedral sites, respectively. Additionally, one satellite peak appeared at $719.1 \mathrm{eV}$, which was further proof for the existence of $\mathrm{Fe}^{3+}$. The $\mathrm{O} 1 \mathrm{~s}$ peaks at 529.5 and $531.1 \mathrm{eV}$ were assigned to lattice oxygen and surface adsorbed oxygen, respectively. The results are consistent with the Mössbauer fit results that spinel structured cobalt ferrite with some degree of inversion was observed. Similar spectra were obtained on the sample CFA-500 (Figure S1), revealing that the main phase of samples obtained under air was cobalt ferrite. 

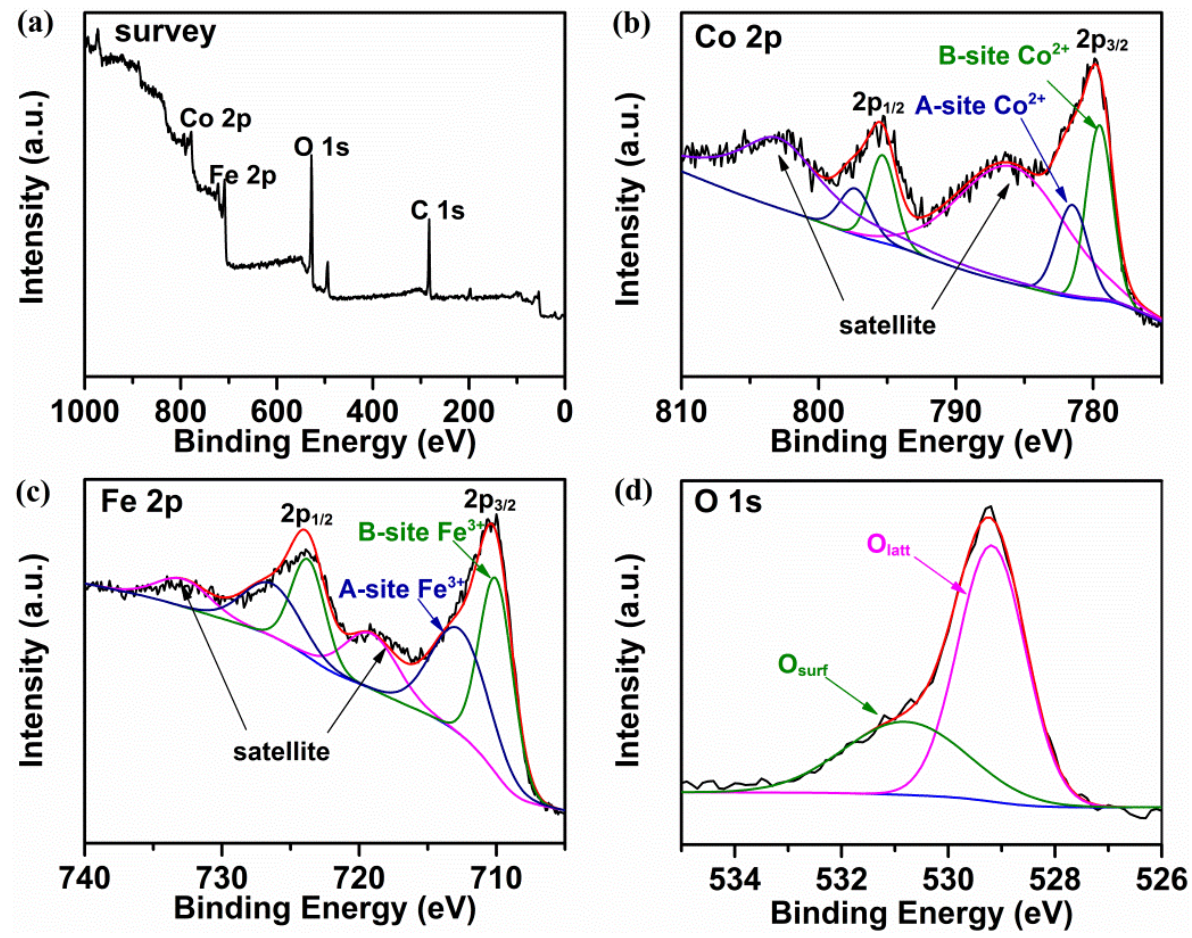

Figure 6. XPS spectra of CFA-600 in different regions (a) survey; (b) Co 2p; (c) Fe 2p and (d) O 1s.

XPS of CFN samples were also studied, as shown in Figure S2 and Figure 7. Due to the limited penetration depth (less than $10 \mathrm{~nm}$ ), XPS analysis reflects only surface composition characteristics. Thus, although the XRD patterns suggested the presence of significant amounts of Co-Fe alloy, the metal concentrations of $\mathrm{Co}$ and $\mathrm{Fe}$ on the surface were so low that we cannot observe corresponding strong XPS signals on CFN-500, as reflected by the low detected Co and Fe atomic contents of $0.32 \%$ and $0.55 \%$, respectively. Carbon was the main species on the surface of CFN-500 and CFN-600. A broad C1s peak suggested four different $C$ species in CFN-500 (Figure S2) in the range of 283-290 eV. The peaks at $284.5,285.5,286.5$ and $288.3 \mathrm{eV}$ were assigned to $\mathrm{C}=\mathrm{C}$ (or $\mathrm{C}-\mathrm{C}$ ), $\mathrm{C}-\mathrm{O}, \mathrm{C}=\mathrm{O}$ or $\mathrm{O}-\mathrm{C}-\mathrm{O}$ and $\mathrm{O}-\mathrm{C}=\mathrm{O}$, respectively [32]. However, the $\mathrm{Co} 2 \mathrm{p}$ and $\mathrm{Fe} 2 \mathrm{p}$ peaks could be distinguished evidently on CFN-600 (Figure 7), maybe because of the relatively higher contents of $\mathrm{Co}(2.86 \%)$ and $\mathrm{Fe}(3.87 \%)$ on the surface. The $\mathrm{Co} 2 \mathrm{p}_{3 / 2}$ peaks at 778.2 and $781.1 \mathrm{eV}$ were ascribed to $\mathrm{Co}^{0}$ and $\mathrm{Co}^{2+}$, respectively, with a satellite peak at $786.6 \mathrm{eV}$. As for iron, beside $\mathrm{Fe}^{3+}$, a small amount of $\mathrm{Fe}^{0}$ can be observed through the peak of $708.1 \mathrm{eV}$ [17]. Thus, we can discern that the metals on the surface were oxidized by the ambient air to some extent. Furthermore, only three peaks at about 284.6, 285.4 and $286.2 \mathrm{eV}$ were observed showing a dramatic decrease in carbon-bonded oxygen groups along with the absence of carboxyl group. The results indicate that the carbon species obtained at different carbonization temperatures display different characteristics. In order to illustrate the variation between the CFN-500 and CFN-600, thermal analysis under inert atmosphere with a heating rate of $10{ }^{\circ} \mathrm{C} \min ^{-1}$ was conducted, as shown in Figure S3a. The TGA plots revealed dramatic weight loss from 200 to $600{ }^{\circ} \mathrm{C}$, which can be assigned to the removal or destruction of oxygenated functional groups. Two main endothermic peaks can be observed at about 300 and $530{ }^{\circ} \mathrm{C}$, accompanied by the release of $\mathrm{CO}$ and $\mathrm{CO}_{2}$ as determined with TG-MS technique (Figure S3b), suggesting that carbonization occurred and two different carbon-containing complexes were decomposed during these processes. The appearance of $\mathrm{CO}$ indicated that self-reduction occurred during the calcination, resulting in the formation of $\mathrm{Co}-\mathrm{Fe}$ alloy. Importantly, the second endothermal peak appeared at about $533^{\circ} \mathrm{C}$, clearly revealing that the reducing degree under $600{ }^{\circ} \mathrm{C}$ was higher than that of $500{ }^{\circ} \mathrm{C}$ and that different carbon-bonded groups were found in CFN-500 and CFN-600. 



Figure 7. XPS spectra of CFN-600 in different regions (a) survey; (b) Co 2p; (c) Fe 2p and (d) C 1s.

Chemical states of surface elements in cobalt-iron nanomaterials CFNH-500 and CFNH-600 obtained under ammonia atmosphere are presented in Figure $\mathrm{S} 4$ and Figure 7, respectively. From the survey in Figure 8a, clear peaks of $\mathrm{Co}, \mathrm{Fe}, \mathrm{C}, \mathrm{N}$ and $\mathrm{O}$ were observed, further certifying the successful introduction of element $\mathrm{N}$ through $\mathrm{NH}_{3}$ calcination. High resolution $\mathrm{Co} 2 \mathrm{p}_{3 / 2}$ peaks present at 780.4 and $782.7 \mathrm{eV}$ can be ascribed to $\mathrm{Co}^{2+}$ and $\mathrm{Co}^{3+}$, respectively, with a satellite at $786.6 \mathrm{eV}$ (Figure $8 \mathrm{~b}$ ). Concerning iron, only $\mathrm{Fe}^{3+}$ was detected with a satellite peak at $719.1 \mathrm{eV}$ (Figure 8c). However, peaks of 778.5 and $707.9 \mathrm{eV}$ were also found in the case of CFNH-500 (Figure S4), which can be assigned to metallic $\mathrm{Co}^{0}$ and $\mathrm{Fe}^{0}$, consistent with the XRD result that $\mathrm{Co}-\mathrm{Fe}$ alloy was formed under $500{ }^{\circ} \mathrm{C}$. The appearance of high valence cobalt and iron suggested that the surface of the sample was oxidized when exposed to air, similarly to the case of the CFN samples. In addition to Co and $\mathrm{Fe}$, high resolution XPS peaks of $\mathrm{C}, \mathrm{N}$ and $\mathrm{O}$ were also observed. Peaks centered at 284.6, 285.8, 286.9 and $288.6 \mathrm{eV}$ (Figure $8 \mathrm{~d}$ ) can be attributed to the $\mathrm{C}=\mathrm{C}$ or $\mathrm{C}-\mathrm{C}, \mathrm{C}-\mathrm{O}$ or $\mathrm{C}-\mathrm{N}, \mathrm{C}=\mathrm{O}$ and $\mathrm{O}-\mathrm{C}=\mathrm{O}$, respectively [33,34]. The N1s spectrum (Figure 8e) can be deconvoluted into five peaks centered at 397, 398.6, 400.1, 402.7 and $404.7 \mathrm{eV}$, representing different kinds of nitrogen species and confirming the presence of $\mathrm{N}$ in the sample. The peaks at 397, 400.1, 402.7 and $404.7 \mathrm{eV}$ could be assigned to the pyridinic, pyrrollic, graphitic $\mathrm{N}$ and oxidized pyridinic $\mathrm{N}[35,36]$. The peak at $398.6 \mathrm{eV}$ was ascribed to the pyridinic $\mathrm{N}$ coordinated with $\mathrm{Fe}$ or $\mathrm{Co}$, i.e., $\mathrm{N}-\mathrm{Fe}$ or $\mathrm{N}-\mathrm{Co}$, according to the literatures [36,37]. Less than $10 \%$ of graphitic $\mathrm{N}$ was found. The majority of pyridinic $\mathrm{N}$ resulting from the coordination with metal (Fe or Co) [38], verified the formation of metal nitride. The O 1s peaks at 530.0 and $531.7 \mathrm{eV}$ (Figure 8f) were ascribed to the lattice oxygen coordinated with metal and surface hydroxyl oxygen, respectively [39]. It should be noted that a peak at $536.0 \mathrm{eV}$, which may originate from organics residuals such as carboxyl groups, was also detected for both CFNH-500 and CFNH-600. 

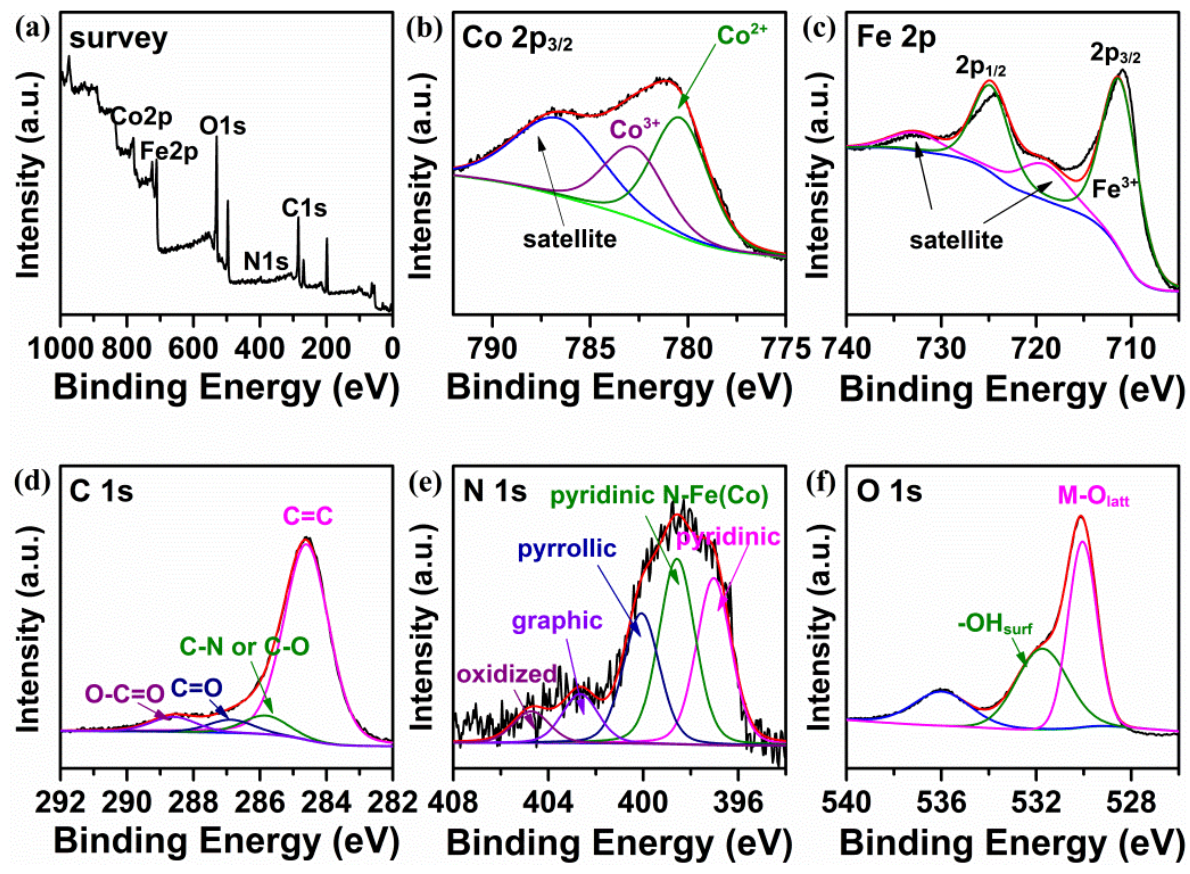

Figure 8. XPS spectra of CFNH-600 in different regions (a) survey; (b) Co 2p; (c) Fe 2p; (d) C 1s; (e) N 1s and (f) $\mathrm{O} 1 \mathrm{~s}$.

\subsection{Catalytic Degradation of Orange II Solutions}

In order to recognize and clarify the PMS activation performance of different types of $\mathrm{Co} / \mathrm{Fe}$-based catalysts (i.e., oxide, alloy and nitride), the samples calcined at $600{ }^{\circ} \mathrm{C}$ under different atmospheres were chosen to catalyze PMS activation for Orange II degradation. According to Figure 9A, no degradation can be obtained during the tested time if there are no catalysts in the system (curve a), suggesting the important role of catalysts. The catalysts cannot provide obvious removal of Orange II without PMS (see from the adsorption stage of $30 \mathrm{~min}$ before zero point of $x$ axis), suggesting that the contribution from adsorption could be negligible. Noticeably, there was about $10 \%$ dye removal on the CFN-600, which may have resulted from the existence of carbon. After PMS addition, the removal rate of Orange II on the catalysts calcined under $\mathrm{N}_{2}$ (CFN-600) was significantly higher than that of CFA-600 and CFNH-600. CFN-600 was able to effectively degrade Orange II through activating PMS to produce oxidizing species, with more than $90 \%$ removal within $10 \mathrm{~min}$. For the CFNH-600, whose catalytic performance was evidently inferior to CFN-600, $80 \mathrm{~min}$ was needed to realize the same efficiency. However, the removal rate was less than $50 \%$ even at the time of 90 min on CFA-600, suggesting that the cobalt ferrite exhibited the lowest activity among the three kinds of Co-Fe catalysts. The superior activity of Co-Fe alloy may be a result mainly of the higher reduction ability of the zero valent metal. Besides, according to the ICP results (Table S5), Co-Fe alloy gave more metal ions leaching, which could also contribute to the degradation activity through homogeneous catalysis. In comparison to the spinel, the nitride catalyst displayed superior activity in PMS activation, which may be due to the different adsorption surfaces with PMS molecules endowing the nitride with stronger adsorption energy, longer O-O bond lengths and more transferred electrons [40]. On the whole, according to the activity measurements the Co-Fe alloy provided the highest Orange II removal efficiency and the activity order of the different catalysts is CFN-600 > CFNH-600 > CFA-600.

In order to estimate the kinetic parameter of the degradation reactions, first order kinetics was employed for PMS activated pollutant degradation, with the equation

$$
\ln \left(\frac{c_{0}}{c}\right)=k t
$$


where $k$ is the apparent first order rate constant of Orange II removal, $c_{0}$ is the original concentration of Orange II aqueous solution, $c$ is the real time concentration of Orange II during the reaction, and $t$ is the reaction time. The reaction rate constants (Figure 9B) for CFA-600, CFN-600 and CFNH-600 were estimated to be $0.007\left(R^{2}=0.976\right), 0.322\left(R^{2}=0.939\right)$ and $0.024\left(R^{2}=0.907\right) \mathrm{min}^{-1}$, respectively. Based on the appropriate regression coefficients for the reaction system, the pseudo-first-order kinetic was basically thought to fit well with the experiment. These catalysts yielded results that were similar to those of the previous studies [41,42], where the kinetic rate of organic pollutants was explored in the presence of PMS. The rate constant of CFN-600 was 46 times and 13.4 times higher than that of the CFA-600 and CFNH-600 samples, respectively, suggesting the excellent performance of the $\mathrm{Co} / \mathrm{Fe}$-based catalysts obtained under $\mathrm{N}_{2}$ atmosphere. The catalytic efficiency of Co-Fe nitride was 3.4 times better than the corresponding $\mathrm{CoFe}_{2} \mathrm{O}_{4}$ in this study, clearly revealing the superiority of nitride. The sequence of the catalytic activity of different types of cobalt-iron samples is Co-Fe alloy > Co-Fe nitride $>$ Co-Fe oxide.
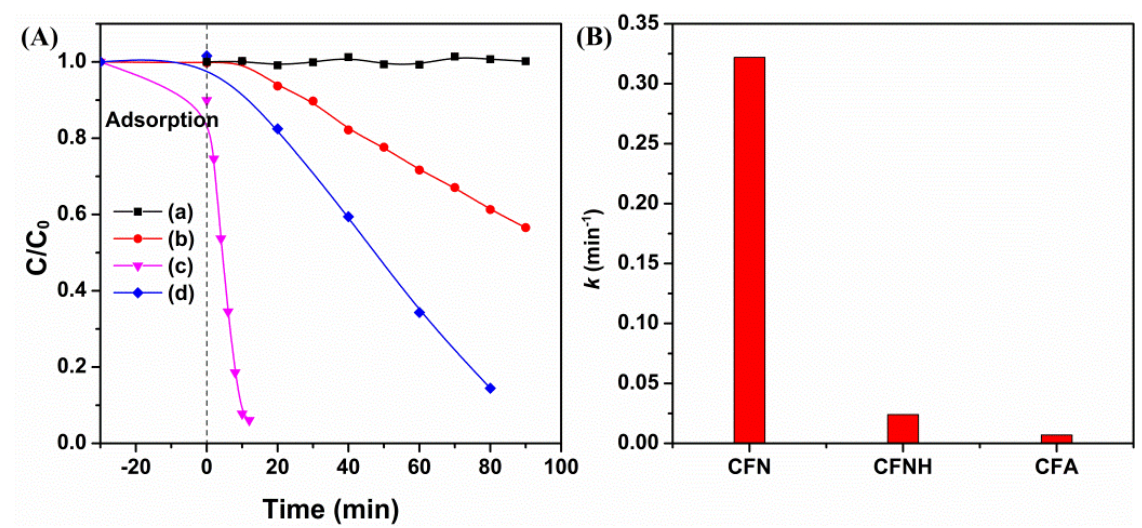

Figure 9. The Orange II degradation curves (A) and reaction rate constants $k$ (B) calculated from $\ln \left(\mathrm{C}_{0} / \mathrm{C}\right)$ versus time curves of PMS activated Orange II degradation processes observed on different samples (a) no catalysts; (b) CFA-600; (c) CFN-600; and (d) CFNH-600. (Conditions: Orange II, $50 \mathrm{mg} \mathrm{L}^{-1}$; Catalysts, $0.1 \mathrm{~g} \mathrm{~L}^{-1}$; Oxone, $0.5 \mathrm{~g} \mathrm{~L}^{-1} ; \mathrm{T}=22 \pm 1{ }^{\circ} \mathrm{C}$ ).

Apart from the excellent catalytic activity, the stability and reusability of a heterogeneous catalyst is also crucial in the catalytic reaction processes. Figure 10 shows the successive test results of the three cobalt-iron catalysts calcined at $600{ }^{\circ} \mathrm{C}$ for Orange II degradation. It can be seen that deactivation took place on the spinel and alloy catalysts during the measured time (Figure 10a,b). At the same time, the nitride kept the original activity, indicating its high stability and reusability (Figure 10c). Previous literature made the point that the formation of $\mathrm{Fe}_{3} \mathrm{C}$ contributed to a better stability in the $\mathrm{Fe}^{0} / \mathrm{Fe}_{3} \mathrm{C} @ \mathrm{CS}$ catalyst [43]; in our case, nitride may play a similar role. Besides, manganese nitride $\left(\mathrm{Mn}_{4} \mathrm{~N}\right)$ was reported to possess good stability compared to the zero valent $\mathrm{Co}$, Fe and Mn in PMS activation for BPA degradation [40]. From the point of view of reusability and stability, Co-Fe nitride exhibited the best performance. According to the XRD patterns (Figure S5) of the used cobalt-iron catalysts, no variation took place in the phase composition compared to the fresh catalysts. However, surface chemical compositions and states of the used catalysts experienced partial oxidation for CFA-600 and CFN-600. In the used CFA-600, a new peak appeared at $783.1 \mathrm{eV}$ representing $\mathrm{Co}^{3+}$ in octahedral site appeared (Figure 11a), indicating the oxidation of $\mathrm{Co}^{2+}$ to $\mathrm{Co}^{3+}$ during the catalytic reaction. This transformation was also reported by Ren et al. who found that $\mathrm{Co}^{3+}$ emerged after PMS activated degradation [18]. Besides, no significant variation took place in the valence state of Fe before and after reaction, since only $\mathrm{Fe}^{3+}$ was observed (Figure 11b). As for CFN-600, the peak of $\mathrm{Co}^{0}$ disappeared, at the same time, the peak at $783.3 \mathrm{eV}$ representing $\mathrm{Co}^{3+}$ turned up compared to the fresh catalyst (Figure 11c). It was demonstrated that metallic $\mathrm{Co}^{0}$ was totally oxidized, and $\mathrm{Co}^{2+}$ was partially oxidized into $\mathrm{Co}^{3+}$ during the catalytic oxidation reaction. Concerning iron, only $\mathrm{Fe}^{3+}$ was 
present in the used catalyst (Figure 11d), manifesting the oxidation of metallic $\mathrm{Fe}^{0}$. It was found that $\mathrm{Fe}^{0}$ was reactive in catalytic PMS activation, being converted to $\mathrm{Fe}(\mathrm{II}) / \mathrm{Fe}(\mathrm{III})$ after the reaction $[43,44]$. These results demonstrated that the active species on the catalyst surface were oxidized to some extent, which was one of the proofs for the deactivation. Besides, according to the XPS results in Figure S6, element sulfur was discovered for the used CFN-600 sample, suggesting that organic compounds were adsorbed on the catalysts, which could be another reason for its deactivation. From the adsorption curves in Figure 10b, the adsorbed amounts of Orange II decreased from run1 to run3, suggesting the decreased adsorption ability and the coverage of the catalyst surface. More importantly, after extending the reaction time to $80 \mathrm{~min}$ (Figure 10d), the CFN-600 sample presented good reusability with no deactivation in run2 and run3, further verifying that adsorbed organics were the main reason for the deactivation testing in a short time (Figure 10b). Thus, surface active sites may be covered by the adsorbed organic compounds during reaction, resulting in the decrease of activity. Similar results were obtained on the CFNH-600 sample (Figure 12a), where sulfur was detected only after reaction. But the small BET surface area of the nitride sample may inhibit the adsorption of organic species from having appreciable impact on the activity of the catalyst, endowing it with better reusability. No significant changes were found on the variation of total pyridinic $\mathrm{N}(59 \pm 2 \%)$, pyrrolic $\mathrm{N}(25 \pm 2 \%)$, graphitic $\mathrm{N}$ $(10 \pm 2 \%)$ and oxidized nitrogen species $(5 \pm 1 \%)$ in the fresh and used catalyst (Table S6), certifying the superior stability of nitrides.

To explore the variation in the chemical state of $\mathrm{Fe},{ }^{57} \mathrm{Fe}$ Mössbauer spectra of the used catalysts were also measured, as shown in Figure 13. For CFA-600, there was no appreciable change detected concerning the $\mathrm{Fe}^{3+}$ species in the spinel, but the relative area fraction of the paramagnetic $\mathrm{Fe}^{3+}$ doublet component increased up to $\sim 2.5 \%$ (Table S2). Similarly, the paramagnetic $\mathrm{Fe}^{3+}$ doublet in CFN-600 increased from $\sim 2 \%$ to $9 \%$ during reaction (Table S3), with a corresponding decrease in metallic $\mathrm{Fe}^{0}$ in the Co-Fe alloy phase, which also refers to the oxidation of catalysts, in agreement with the XPS results. No variation occurred in the state of Fe in CFNH-600, providing further confirmation in the stability of this catalyst. Hence, the good stability and reusability made the nitride more promising in the environmental remediation.
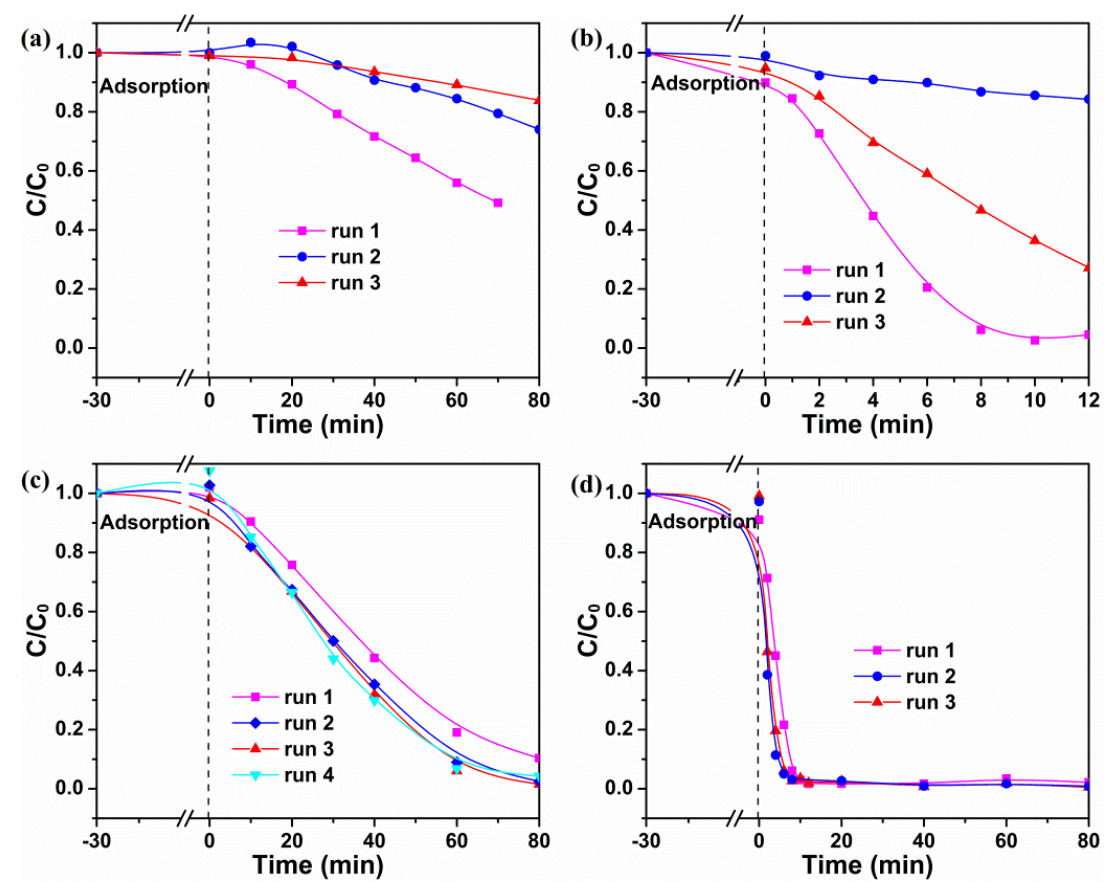

Figure 10. Reusability in Orange II degradation on different samples (a) CFA-600; (b) CFN-600 (14 min); (c) CFNH-600 and (d) CFN-600 (80 min). (Conditions: Orange II, $50 \mathrm{mg} \mathrm{L}^{-1}$; Catalysts, $0.1 \mathrm{~g} \mathrm{~L}^{-1}$; Oxone, $0.5 \mathrm{~g} \mathrm{~L}^{-1}$ ). 

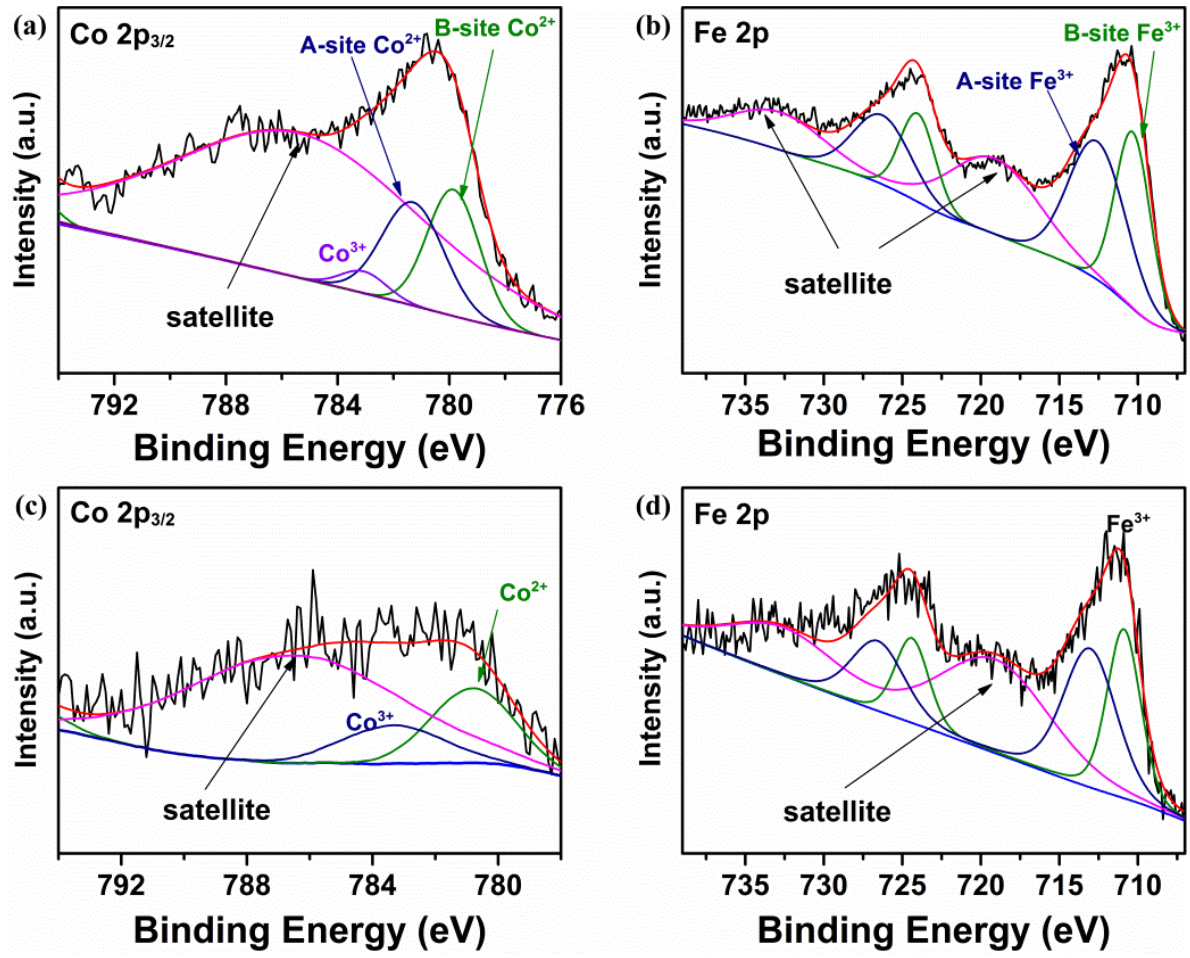

Figure 11. XPS spectra of the used CFA-600 (a) Co 2p $\mathrm{p}_{3 / 2} ;$ (b) Fe 2p and CFN-600 (c) Co 2p $\mathrm{p}_{3 / 2}$; (d) Fe 2p.
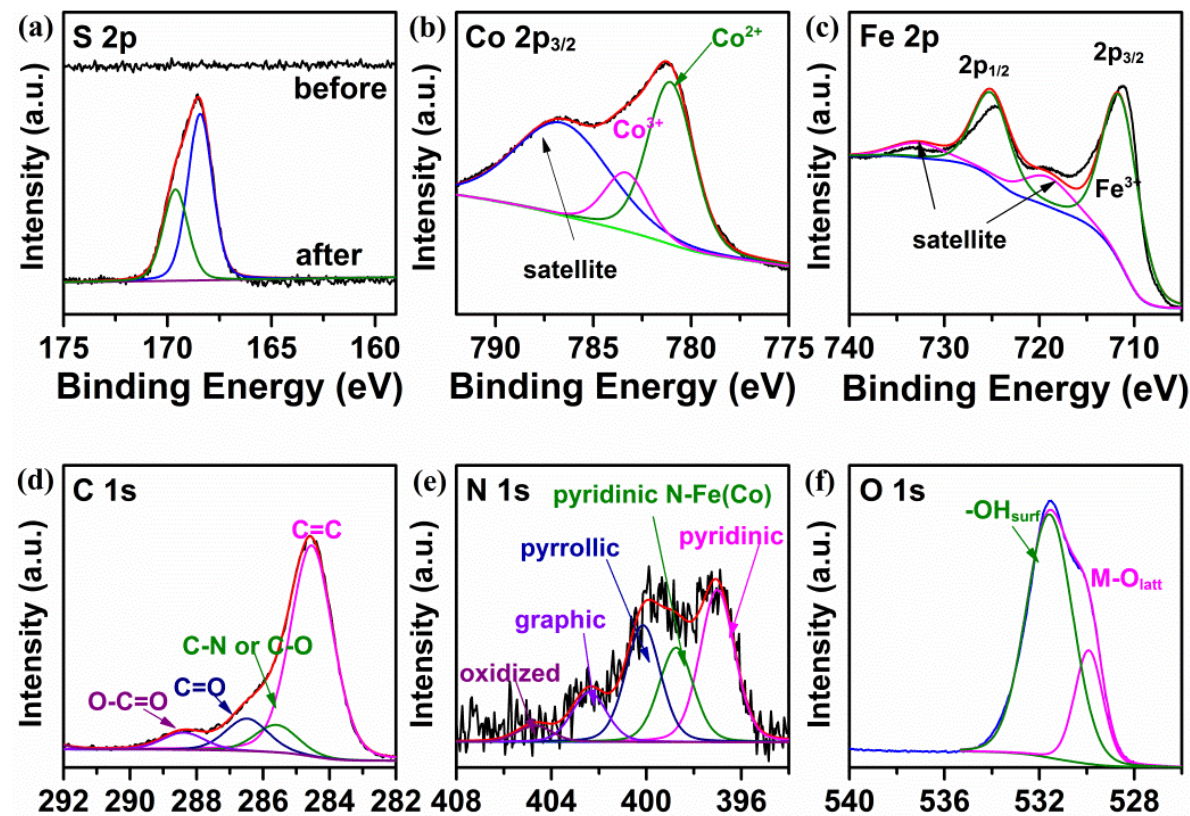

Binding Energy (eV) Binding Energy (eV)

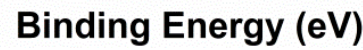

Figure 12. High resolution XPS spectra of the used CFNH-600 in different regions (a) $\mathrm{S} 2 \mathrm{p}$ before and after reaction; (b) Co 2p; (c) Fe 2p; (d) C 1s; (e) N 1s and (f) O 1s. 


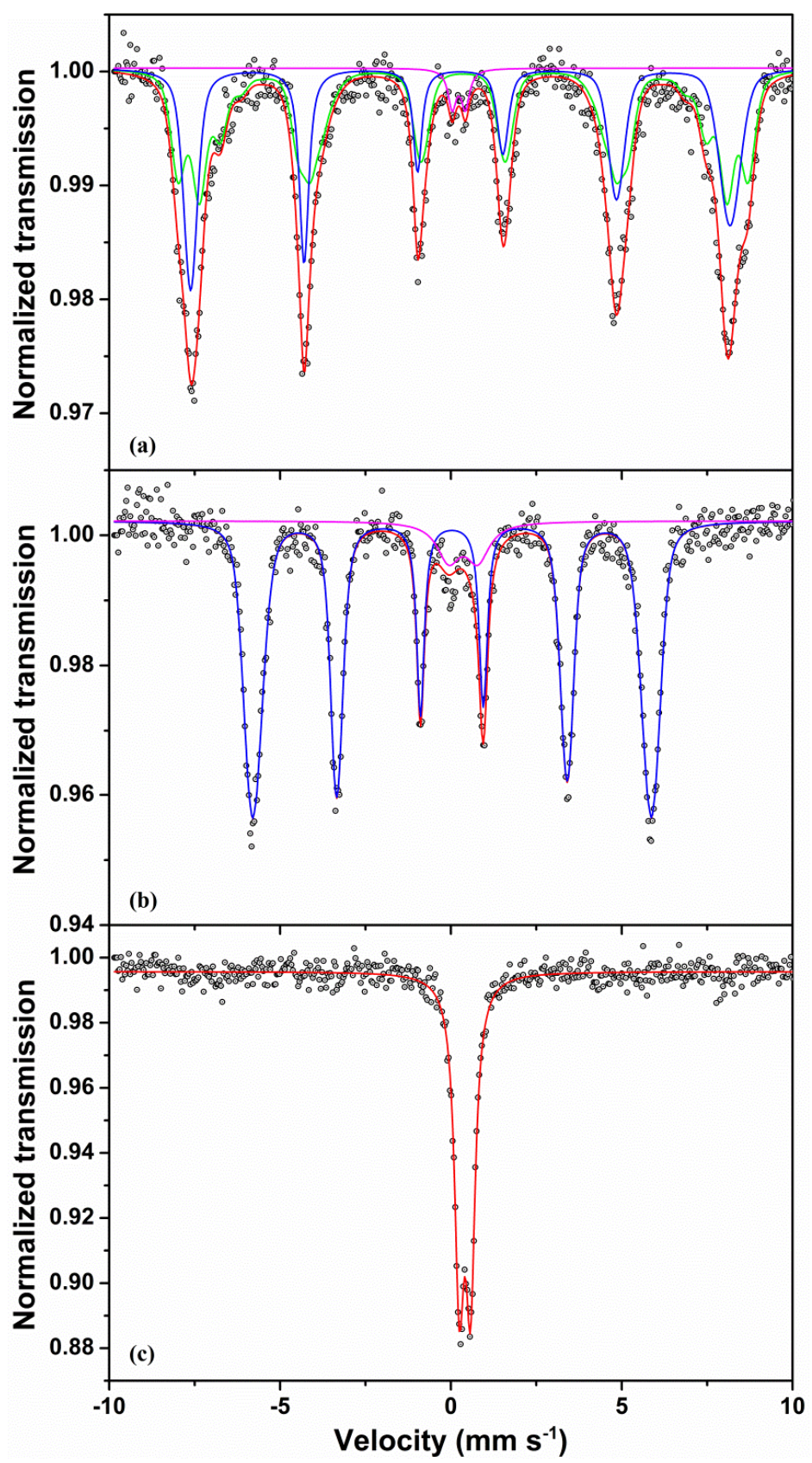

Figure 13. ${ }^{57} \mathrm{Fe}$ Mössbauer spectra of the used CFA-600 (a); CFN-600 (b) and CFNH-600 (c).

\subsection{Reaction Mechanism Study}

Previous investigations have pointed out that in the cobalt-iron homogeneous and heterogeneous catalytic activation of the peroxymonosulfate reaction, sulfate radical $\left(\mathrm{SO}_{4}{ }^{-}\right)$and hydroxyl radical $(\cdot \mathrm{OH})$ can always be identified as the main reactive species [45]. To ascertain the main intermediate active species in the three different systems, radical scavenger tests were taken in this study. It is widely accepted that alcohols with an $\alpha$-hydrogen such as ethanol readily react with both $\mathrm{SO}_{4}{ }^{-}$and . $\mathrm{OH}\left(1.6-7.7 \times 10^{7} \mathrm{M}^{-1} \mathrm{~s}^{-1}\right.$ and 1.2-2.8 $\times 10^{9} \mathrm{M}^{-1} \mathrm{~s}^{-1}$, respectively), while those without $\alpha-\mathrm{H}$, such as tert-butyl alcohol (TBA), react more easily with $\cdot \mathrm{OH}\left(3.8-7.6 \times 10^{8} \mathrm{M}^{-1} \mathrm{~s}^{-1}\right)$, but in a much more slower reaction rate with $\mathrm{SO}_{4}{ }^{--}\left(4.0-9.1 \times 10^{5} \mathrm{M}^{-1} \mathrm{~s}^{-1}\right)[46,47]$. Thus, TBA as a particular scavenger for $\cdot \mathrm{OH}$ and ethanol as a universal scavenger for both $\mathrm{SO}_{4} \cdot{ }^{-}$and $\cdot \mathrm{OH}$ were used to differentiate the contribution of $\mathrm{SO}_{4}{ }^{-}$- from $\cdot \mathrm{OH}$. In the organic degradation process, where radicals played a decisive 
role when the quenching agent was added into the solution, the degradation would be either prevented or significantly reduced. As shown in Figure 14, degradation was inhibited for all three samples with the addition of ethanol. More importantly, there was hardly any effect observed on the CFN-600 sample when using the same amounts of TBA as a scavenger, suggesting that sulfate radical was the main reactive species. As for CFA-600 and CFNH-600, the addition of TBA caused some inhibiting effects in the Orange II degradation efficiency, but ethanol made a more significant contribution. Therefore, we could conclude that sulfate radical played the key role in the CFA-600/PMS and CFNH-600/PMS systems, with a certain amount of hydroxyl radical; only sulfate radical played a role as reactive species in the CFN-600/PMS system.
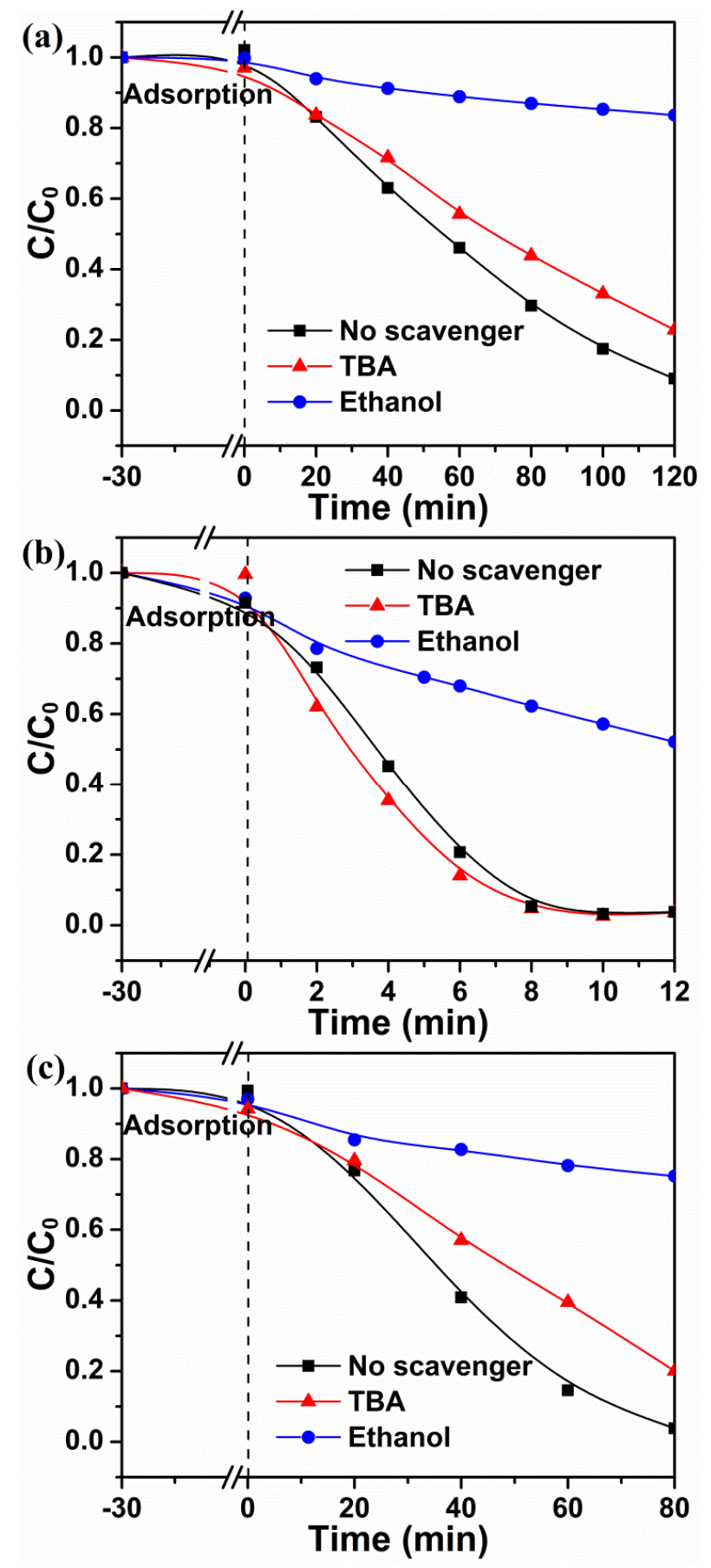

Figure 14. Radical scavenger tests of (a) CFA-600; (b) CFN-600 and (c) CFNH-600. 
In the past years, several investigations have been carried out to recognize the mechanism of $\mathrm{Co} / \mathrm{Fe}$-based catalysts in the activation of PMS. It has been reported that when $\mathrm{CoFe}_{2} \mathrm{O}_{4}$ was used as a catalyst for PMS activation, cobalt mainly presented as $\mathrm{Co}^{2+}$ before reaction, and it underwent partial transformation to $\mathrm{Co}^{3+}$ after catalytic reaction, in which the involvement of $\mathrm{Co}^{2+}-\mathrm{Co}^{3+}-\mathrm{Co}^{2+}$ redox processes were proposed during the reaction [18]. In addition, sulfate radical was found to be generated as the main active species in oxone activation by cobalt-iron oxides [22,48]. Concerning the CFA sample in the present study, the reaction mechanism for Orange II degradation can be proposed as following (Equations (2) (7)).

$$
\begin{aligned}
\equiv \mathrm{Co}^{2+}+\mathrm{HSO}_{5}{ }^{-} \rightarrow \equiv \mathrm{Co}^{3+}+\mathrm{SO}_{4}{ }^{--}+\mathrm{OH}^{-} \\
\equiv \mathrm{Fe}^{2+}+\mathrm{HSO}_{5}{ }^{-} \rightarrow \equiv \mathrm{Fe}^{3+}+\mathrm{SO}_{4}{ }^{-}+\mathrm{OH}^{-} \\
\equiv \mathrm{Co}^{3+}+\mathrm{HSO}_{5}{ }^{-} \rightarrow \equiv \mathrm{Co}^{2+}+\mathrm{SO}_{5}^{--}+\mathrm{H}^{+} \\
\equiv \mathrm{Fe}^{3+}+\mathrm{HSO}_{5}{ }^{-} \rightarrow \equiv \mathrm{Fe}^{2+}+\mathrm{SO}_{5}{ }^{--}+\mathrm{H}^{+} \\
\equiv \mathrm{Fe}^{2+}+\equiv \mathrm{Co}^{3+} \rightarrow \equiv \mathrm{Co}^{2+}+\equiv \mathrm{Fe}^{3+} \\
\mathrm{SO}_{4}{ }^{--}+\text {Orange II } \rightarrow \text { many steps } \rightarrow \mathrm{CO}_{2}+\mathrm{H}_{2} \mathrm{O}+\mathrm{SO}_{4}{ }^{2-}
\end{aligned}
$$

It was reported that the active sites are mainly the cobalt and iron ions in the spinel type $\mathrm{CoFe}_{2} \mathrm{O}_{4}$ and the zero-valent cobalt and iron for the octahedral $\mathrm{CoFe} / \mathrm{CoFe}_{2} \mathrm{O}_{4}$ submicron composite [17]. In the case of the CFN sample, the following reactions (Equations (8) (11)) may be considered, with the rest of the steps being identical to processes described by Equations (2) (7) above.

$$
\begin{gathered}
\equiv \mathrm{Co}^{0}+2 \mathrm{HSO}_{5}{ }^{-} \rightarrow \equiv \mathrm{Co}^{2+}+2 \mathrm{SO}_{4}^{--}+2 \mathrm{OH}^{-} \\
\equiv \mathrm{Fe}^{0}+2 \mathrm{HSO}_{5}^{-} \rightarrow \equiv \mathrm{Fe}^{2+}+3 \mathrm{SO}_{4}^{--}+2 \mathrm{OH}^{-} \\
\equiv \mathrm{Co}^{0}+2 \equiv \mathrm{Co}^{3+} \rightarrow 3 \equiv \mathrm{Co}^{2+} \\
\equiv \mathrm{Fe}^{0}+2 \equiv \mathrm{Fe}^{3+} \rightarrow 3 \equiv \mathrm{Fe}^{2+}
\end{gathered}
$$

For the Co-Fe nitride, the redox process of $\mathrm{Co}^{2+}-\mathrm{Co}^{3+}-\mathrm{Co}^{2+}$ also exist in the system, and one can observe only small changes in the relative amounts of $\mathrm{Co}^{2+}$ and $\mathrm{Co}^{3+}$ according to the XPS fitting results of the CFNH- 600 before and after reaction. The potential mechanism could be speculated to be similar to that mentioned for the CFA sample, except that the introduction of $\mathrm{N}$ into the catalyst made its stability appreciable, and at the same time, the activity superior to the oxide.

\section{Materials and Methods}

\subsection{Chemicals}

Cobalt acetylacetonate $\left(\mathrm{Co}(\mathrm{acac})_{2}\right)$, ferric acetylacetonate ((Fe(acac) $\left.)_{3}\right)$, Orange II sodium salt $\left(\mathrm{C}_{16} \mathrm{H}_{11} \mathrm{~N}_{2} \mathrm{NaO}_{4} \mathrm{~S}\right)$ and tert-butyl alcohol (TBA, $>99.5 \%$ ) were purchased from Aladdin Chemistry Co. Ltd. (Shanghai, China) 2-ethoxyethanol $\left(\mathrm{C}_{4} \mathrm{H}_{10} \mathrm{O}_{2}\right)$ and methanol $\left(\mathrm{CH}_{3} \mathrm{OH}, \geq 99.5 \%\right)$ were purchased from Tianjin Damao Chemical Reagent Company (Tianjin, China) and $\mathrm{H}_{2} \mathrm{O}_{2}$ (30 wt.\%) from Tianjin Kermel Chemical Reagent Company (Tianjin, China). PMS was purchased from Alfa Aesar (Tianjin, China). Ethanol $\left(\mathrm{CH}_{3} \mathrm{CH}_{2} \mathrm{OH}, \geq 99.7 \%\right)$ was obtained from Sinopharm Chemical Reagent Co. Ltd. (Shanghai, China). All the chemicals were analytical grade with no further treatment. Deionized water was used for solution preparation.

\subsection{Synthesis of Cobalt-Iron Catalysts}

$\mathrm{Co} / \mathrm{Fe}$-based catalysts were prepared through an extended soft chemical solution process reported previously $[49,50]$. Typically, $\mathrm{Co}(\mathrm{acac})_{2}$ and $\mathrm{Fe}(\mathrm{acac})_{3}$ (molar ratio 1:2) were first dissolved 
homogeneously together in $50 \mathrm{~mL}$ 2-ethoxyethanol within $1 \mathrm{~L}$ beaker at $50{ }^{\circ} \mathrm{C}$, followed by slow addition of $30 \mathrm{~mL} \mathrm{H}_{2} \mathrm{O}_{2}$ aqueous solution under magnetic stirring. The suspension was obtained after rotary evaporation and drying. Finally, the catalysts were obtained by calcining the solid precursors at 500 or $600{ }^{\circ} \mathrm{C}$ under special atmosphere. The prepared cobalt ferrite samples are denoted as CFX-T, where $X$ represents the calcination atmosphere of air $(\mathrm{A})$, nitrogen $(\mathrm{N})$ and ammonia $(\mathrm{NH})$ and $T$ represents the final calcination temperature.

\subsection{Catalysts Characterization}

The X-ray diffraction (XRD) patterns were measured on a PW3040/60 X'Pert PRO diffractometer (PANalytical, Alemlo, The Netherlands) equipped with a copper target $(\mathrm{Cu} K \alpha$ radiation, $\lambda=1.5406 \AA$ ) at an accelerating voltage of $40 \mathrm{kV}$, a current of $40 \mathrm{~mA}$, and a scanning $2 \theta$ range of $10^{\circ}-80^{\circ}$ at room temperature. The average crystallite sizes were calculated by Scherrer equation as below:

$$
\varphi=\frac{K \lambda}{\beta \cos \theta}
$$

where $\varphi$ is the average crystallite size, $K$ is the Scherrer constant (taken to be equal to 0.89 ); $\lambda$ is the wavelength of the used X-ray, $\theta$ is the diffraction angle of the calculated peak, and $\beta$ is the full width at half maximum height (FWHM) of the mean intensity peak. The morphological feature was observed on a JEM-2000EX electronic microscope (JEOL, Tokyo, Japan) with an accelerating voltage of $120.0 \mathrm{kV}$. The sample was dispersed in the ethanol solution and then withdrawn to drop on a copper grid for measurement. The field-emission scanning electron microscopy (FESEM, JSM-7800F) (JEOL, Tokyo, Japan) was operated at an accelerating voltage of $3.0 \mathrm{kV}$, and the sample was put onto a conductive carbon tape to be measured. Textural information was measured by nitrogen adsorption/desorption at $77 \mathrm{~K}$ using a Micromeritics ASAP 2460 apparatus (Micromeritics, Norcross, GA, USA). Prior to measurement, all the samples were pretreated in vacuum at $110^{\circ} \mathrm{C}$ for $1 \mathrm{~h}$, followed by $300{ }^{\circ} \mathrm{C}$ for $6 \mathrm{~h}$. The thermogravimetric and differential scanning calorimetry (TG-DSC) curves in $\mathrm{N}_{2}$ were investigated on a TGA instrument Q600 (TA, New Castle, PA, USA) with alumina crucible as sample holder, and the heating rate was set at $10{ }^{\circ} \mathrm{C} \mathrm{min}^{-1}$ with flow rate of $100 \mathrm{~mL} \mathrm{~min}^{-1}$. The metal ion leaching amount after reaction was determined by inductively coupled plasma-atomic emission spectrometry (ICP-AES) on an IRIS Intrepid II XSP instrument (rThermoFisher, Waltham, MA, USA). The X-ray photoelectron spectroscopy (XPS) experiment was performed on an ESCALAB250 X-ray photoelectron spectrometer (ThermoFisher, Waltham, MA, USA) with monochromatic Al K $\alpha$ as the X-ray source, and contaminated carbon was used as the internal standard $(\mathrm{C} 1 \mathrm{~s}=284.6 \mathrm{eV}) .{ }^{57} \mathrm{Fe}$ Mössbauer spectra were measured on a Topologic 500A spectrometer employing a ${ }^{57} \mathrm{Co}(\mathrm{Rh})$ as $\gamma$-ray radioactive source moving in a constant acceleration mode at room temperature. The spectra were fitted by using the MossWinn 4.0 program [51]. Room temperature $\alpha$-iron foil was applied for the calibration of the velocity axis, and

${ }^{57} \mathrm{Fe}$ isomer shift values are quoted relative to that of the standard.

\subsection{Activity Evaluation}

The prepared cobalt-iron catalysts were applied in catalytic degradation of Orange II by activation of PMS. All the experiments were carried out in a beaker with constant rotation speed. Prior to the degradation experiments, proper amounts of catalyst were mixed with Orange II solution under stirring for $30 \mathrm{~min}$ to achieve adsorption-desorption equilibrium, and then PMS was added into the system to initiate the reaction. The typical concentrations of catalyst, PMS and Orange II were $0.1 \mathrm{~g} \mathrm{~L}^{-1}, 0.5 \mathrm{~g} \mathrm{~L}^{-1}$ and $50 \mathrm{mg} \mathrm{L}^{-1}$, respectively. At certain time intervals, $1 \mathrm{~mL}$ reaction solution was withdrawn and quenched immediately by adding $1 \mathrm{~mL}$ methanol solution. After centrifugation, the supernatant was analyzed by the GBC Cintra apparatus to record variation of the absorption peak intensity (wavelength at $484 \mathrm{~nm}$ for Orange II aqueous solution). 


\section{Conclusions}

Three kinds of cobalt-iron catalysts with the dominant phase of $\mathrm{CoFe}_{2} \mathrm{O}_{4}$ spinel, $\mathrm{Co}-\mathrm{Fe}$ alloy and Co-Fe nitride were successfully synthesized through extended soft chemical solution processes followed by atmosphere-dependent calcination. All these obtained catalysts were applied to the Orange II degradation by PMS activation and performed good pollutants removal efficiency. By comparison, Co-Fe alloy exhibited the best activity and Co-Fe nitride possessed very good stability. Sulfate radical was proved to be the main active species in Co-Fe alloy system, while hydroxyl radical is also effective in the $\mathrm{Co}-\mathrm{Fe}$ nitride and $\mathrm{CoFe}_{2} \mathrm{O}_{4}$ participant reactions. Considering the severe leaching problem of the zero valent metals, efforts need to be made to retard the leaching problem and improve the stability. Besides, the detailed properties and mechanisms of the catalysts especially for the nitride-derived catalysts need to be further explored.

Supplementary Materials: The following are available online at www.mdpi.com/2073-4344/7/5/138/S1, Figure S1: XPS spectra of CFA-500 in different regions (a) survey, (b) C 1s, (c) Co 2p, (d) Fe 2p. Figure S2: XPS spectra of CFN-500 in different regions (a) survey, (b) Co 2p, (c) Fe 2p, and (d) C 1s.Figure S3: TG-DSC (a) and the TG-MS (b) curves of the as-prepared cobalt-iron nanomaterials under Ar atmosphere. Figure S4: XPS spectra of CFNH-500 in different regions (a) survey, (b) Co 2p, (c) Fe 2p, (d) C 1s, (e) N 1s and (f) O 1s. Figure S5: XRD patterns of the used CFA-600, CFN-600 and CFNH-600. Figure S6: S2p XPS spectrum of the CFN-600 before and after reaction. Table S1: The BET surface area and pore volume of prepared samples. Table S2: ${ }^{57} \mathrm{Fe}$ Mössbauer parameters of the samples CFA-500 and CFA-600 as well as CFA-600-after reaction derived on the basis of Mössbauer spectra recorded at room temperature. Table S3: ${ }^{57} \mathrm{Fe}$ Mössbauer parameters of the samples CFN-500 and CFN-600 as well as CFN-600-after reaction derived on the basis of Mössbauer spectra recorded at room temperature. Table S4: ${ }^{57} \mathrm{Fe}$ Mössbauer parameters of the samples CFNH-500 and CFNH-600 derived on the basis of Mössbauer spectra recorded at room temperature. Table S5: Metal leaching concentrations detected by ICP. Table S6: XPS fitting results of surface elements for the CFA-600, CFN-600 and CFNH-600 samples before and after reaction.

Acknowledgments: This work was supported by the National Natural Science Foundation of China [grant numbers 21476232, 21403220, 2161101071], China Ministry of Science and Technology [grant number 2016YFA0202804] and the CAS President's International Fellowship Initiative (PIFI) program for a postdoctoral researcher funded by the Chinese Academy of Sciences [grant number 2016PT023].

Author Contributions: K.Z. and J.W. conceived and designed the experiments; K.Z. performed the experiments; K.Z. C.J. and Z.K. analyzed the data; K.Z. wrote the paper; A.S.G. contributed to the data analysis and paper revision.

Conflicts of Interest: The authors declare no conflict of interest.

\section{References}

1. Cizmas, L.; Sharma, V.K.; Gray, C.M.; McDonald, T.J. Pharmaceuticals and personal care products in waters: Occurrence, toxicity, and risk. Environ. Chem. Lett. 2015, 13, 381-394. [CrossRef]

2. Cheng, M.; Zeng, G.; Huang, D.; Lai, C.; Xu, P.; Zhang, C.; Liu, Y. Hydroxyl radicals based advanced oxidation processes (AOPs) for remediation of soils contaminated with organic compounds: A review. Chem. Eng. J. 2016, 284, 582-598. [CrossRef]

3. Zhang, B.T.; Zhang, Y.; Teng, Y.H.; Fan, M.H. Sulfate radical and its application in decontamination technologies. Crit. Rev. Envrion. Sci. Technol. 2015, 45, 1756-1800. [CrossRef]

4. Hu, P.; Long, M. Cobalt-catalyzed sulfate radical-based advanced oxidation: A review on heterogeneous catalysts and applications. Appl. Catal. B 2016, 181, 103-117. [CrossRef]

5. Chan, K.H.; Chu, W. Degradation of atrazine by cobalt-mediated activation of peroxymonosulfate: Different cobalt counteranions in homogenous process and cobalt oxide catalysts in photolytic heterogeneous process. Water Res. 2009, 43, 2513-2521. [CrossRef] [PubMed]

6. Qi, F.; Chu, W.; Xu, B.B. Modeling the heterogeneous peroxymonosulfate/Co-MCM41 process for the degradation of caffeine and the study of influence of cobalt sources. Chem. Eng. J. 2014, 235, 10-18. [CrossRef]

7. Cai, C.; Zhang, H.; Zhong, X.; Hou, L.W. Ultrasound enhanced heterogeneous activation of peroxymonosulfate by a bimetallic Fe-Co/SBA-15 catalyst for the degradation of orange II in water. J. Hazard. Mater. 2015, 283, 70-79. [CrossRef] [PubMed] 
8. Zhou, G.; Zhou, L.; Sun, H.; Ang, H.M.; Tadé, M.O.; Wang, S. Carbon microspheres supported cobalt catalysts for phenol oxidation with peroxymonosulfate. Chem. Eng. Res. Des. 2015, 101, 15-21. [CrossRef]

9. Duan, X.; Ao, Z.; Sun, H.; Zhou, L.; Wang, G.; Wang, S. Insights into N-doping in single-walled carbon nanotubes for enhanced activation of superoxides: A mechanistic study. Chem. Commun. 2015, 51, 15249-15252. [CrossRef] [PubMed]

10. Duan, X.; Ao, Z.; Zhou, L.; Sun, H.; Wang, G.; Wang, S. Occurrence of radical and nonradical pathways from carbocatalysts for aqueous and nonaqueous catalytic oxidation. Appl. Catal. B 2016, 188, 98-105. [CrossRef]

11. Duan, X.; O’Donnell, K.; Sun, H.; Wang, Y.; Wang, S. Sulfur and nitrogen co-doped graphene for metal-free catalytic oxidation reactions. Small 2015, 11, 3036-3044. [CrossRef] [PubMed]

12. Duan, X.; Sun, H.; Ao, Z.; Zhou, L.; Wang, G.; Wang, S. Unveiling the active sites of graphene-catalyzed peroxymonosulfate activation. Carbon 2016, 107, 371-378. [CrossRef]

13. Sun, H.Q.; Liu, S.Z.; Zhou, G.L.; Ang, H.M.; Tade, M.O.; Wang, S.B. Reduced graphene oxide for catalytic oxidation of aqueous organic pollutants. ACS Appl. Mater. Interfaces 2012, 4, 5466-5471. [CrossRef] [PubMed]

14. Sharma, R.; Kumar, V.; Bansal, S.; Singhal, S. Assortment of magnetic nanospinels for activation of distinct inorganic oxidants in photo-fenton's process. J. Mol. Catal. A Chem. 2015, 402, 23-63. [CrossRef]

15. Yang, Q.; Choi, H.; Al-Abed, S.R.; Dionysiou, D.D. Iron-cobalt mixed oxide nanocatalysts: Heterogeneous peroxymonosulfate activation, cobalt leaching, and ferromagnetic properties for environmental applications. Appl. Catal. B 2009, 88, 462-469. [CrossRef]

16. Hu, L.X.; Yang, F.; Zou, L.P.; Yuan, H.; Hu, X. Fe/SBA-15 catalyst coupled with peroxymonosulfate for heterogeneous catalytic degradation of rhodamine B in water. Chin. J. Catal. 2015, 36, 1785-1797. [CrossRef]

17. Sun, H.; Yang, X.; Zhao, L.; Xu, T.; Lian, J. One-pot hydrothermal synthesis of octahedral CoFe $/ \mathrm{CoFe}_{2} \mathrm{O}_{4}$ submicron composite as heterogeneous catalysts with enhanced peroxymonosulfate activity. J. Mater. Chem. A 2016, 4, 9455-9465. [CrossRef]

18. Ren, Y.M.; Lin, L.Q.; Ma, J.; Yang, J.; Feng, J.; Fan, Z.J. Sulfate radicals induced from peroxymonosulfate by magnetic ferrospinel $\mathrm{MFe}_{2} \mathrm{O}_{4}(\mathrm{M}=\mathrm{Co}, \mathrm{Cu}, \mathrm{Mn}$ and $\mathrm{Zn})$ as heterogeneous catalysts in the water. Appl. Catal. $B$ 2015, 165, 572-578. [CrossRef]

19. Xu, L.J.; Chu, W.; Gan, L. Environmental application of graphene-based $\mathrm{CoFe}_{2} \mathrm{O}_{4}$ as an activator of peroxymonosulfate for the degradation of a plasticizer. Chem. Eng. J. 2015, 263, 435-443. [CrossRef]

20. El-Shobaky, G.A.; Turky, A.M.; Mostafa, N.Y.; Mohamed, S.K. Effect of preparation conditions on physicochemical, surface and catalytic properties of cobalt ferrite prepared by coprecipitation. J. Alloys Compd. 2010, 493, 415-422. [CrossRef]

21. Ding, Z.; Wang, W.; Zhang, Y.; Li, F.; Liu, J.P. Synthesis, characterization and adsorption capability for Congo Red of $\mathrm{CoFe}_{2} \mathrm{O}_{4}$ ferrite nanoparticles. J. Alloys Compd. 2015, 640, 362-370. [CrossRef]

22. Wei, G.L.; Liang, X.L.; He, Z.S.; Liao, Y.S.; Xie, Z.Y.; Liu, P.; Ji, S.C.; He, H.P.; Li, D.Q.; Zhang, J. Heterogeneous activation of oxone by substituted magnetites $\mathrm{Fe}_{3-\mathrm{x}} \mathrm{M}_{\mathrm{x}} \mathrm{O}_{4}(\mathrm{Cr}, \mathrm{Mn}, \mathrm{Co}, \mathrm{Ni})$ for degradation of acid orange II at neutral pH. J. Mol. Catal. A Chem. 2015, 398, 86-94. [CrossRef]

23. Yu, F.H.; Wang, J.H.; Zhao, K.F.; Yin, J.; Jin, C.Z.; Liu, X. A novel approach for the preparation of phase-tunable $\mathrm{TiO}_{2}$ nanocomposite crystals with superior visible-light-driven photocatalytic activity. Chin. J. Catal. 2013, 34, 1216-1223. [CrossRef]

24. Yu, F.; Wang, Y.; Tang, H.; Zhang, Y.; Jin, C.; Liu, X.; Li, M.; Wang, J. Synergic effect of cation doping and phase composition on the photocatalytic performance of $\mathrm{TiO}_{2}$ under visible light. Catal. Commun. 2014, 51, 46-52. [CrossRef]

25. Wang, Y.; Zhang, Y.; Yu, F.; Jin, C.; Liu, X.; Ma, J.; Wang, Y.; Huang, Y.; Wang, J. Correlation investigation on the visible-light-driven photocatalytic activity and coordination structure of rutile $\mathrm{Sn}-\mathrm{Fe}-\mathrm{TiO}_{2}$ nanocrystallites for methylene blue degradation. Catal. Today 2015, 258, 112-119. [CrossRef]

26. Zhu, K.; Wang, J.; Wang, Y.; Jin, C.; Ganeshraja, A.S. Visible-light-induced photocatalysis and peroxymonosulfate activation over $\mathrm{ZnFe}_{2} \mathrm{O}_{4}$ fine nanoparticles for degradation of orange II. Catal. Sci. Technol. 2016, 6, 2296-2304. [CrossRef]

27. Sawatzky, G.A.; Van Der Woude, F.; Morrish, A.H. Cation distributions in octahedral and tetrahedral sites of the ferrimagnetic spinel $\mathrm{CoFe}_{2} \mathrm{O}_{4}$. J. Appl. Phys. 1968, 39, 1204-1206. [CrossRef]

28. Le Trong, H.; Presmanes, L.; De Grave, E.; Barnabé, A.; Bonningue, C.; Tailhades, P. Mössbauer characterisations and magnetic properties of iron cobaltites $\mathrm{Co}_{\mathrm{x}} \mathrm{Fe}_{3-\mathrm{x}} \mathrm{O}_{4}(1 \leq \mathrm{x} \leq 2.46)$ before and after spinodal decomposition. J. Magn. Magn. Mater. 2013, 334, 66-73. [CrossRef] 
29. Klencsár, Z.; Németh, P.; Sándor, Z.; Horváth, T.; Sajó, I.E.; Mészáros, S.; Mantilla, J.; Coaquira, J.A.H.; Garg, V.K.; Kuzmann, E.; et al. Structure and magnetism of Fe-Co alloy nanoparticles. J. Alloys Compd. 2016, 674, 153-161. [CrossRef]

30. Bainbridge, J.; Channing, D.A.; Whitlow, W.H.; Pendlebury, R.E. A Mössbauer and X-ray investigation of zeta $\mathrm{Fe}_{2}$ N. J. Phys. Chem. Solids 1973, 34, 1579-1580. [CrossRef]

31. Wang, W.P.; Yang, H.; Xian, T.; Jiang, J.L. Xps and magnetic properties of $\mathrm{CoFe}_{2} \mathrm{O}_{4}$ nanoparticles synthesized by a polyacrylamide gel route. Mater. Trans. 2012, 53, 1586-1589. [CrossRef]

32. Indrawirawan, S.; Sun, H.; Duan, X.; Wang, S. Nanocarbons in different structural dimensions (0-3D) for phenol adsorption and metal-free catalytic oxidation. Appl. Catal. B 2015, 179, 352-362. [CrossRef]

33. Yang, S.; Li, L.; Xiao, T.; Zhang, Y.; Zheng, D. Promoting effect of ammonia modification on activated carbon catalyzed peroxymonosulfate oxidation. Sep. Purif. Technol. 2016, 160, 81-88. [CrossRef]

34. Li, Y.; Zhou, W.; Wang, H.; Xie, L.; Liang, Y.; Wei, F.; Idrobo, J.C.; Pennycook, S.J.; Dai, H. An oxygen reduction electrocatalyst based on carbon nanotube-graphene complexes. Nat. Nanotechnol. 2012, 7, 394-400. [CrossRef] [PubMed]

35. Jaouen, F.; Herranz, J.; Lefevre, M.; Dodelet, J.P.; Kramm, U.I.; Herrmann, I.; Bogdanoff, P.; Maruyama, J.; Nagaoka, T.; Garsuch, A.; et al. Cross-laboratory experimental study of non-noble-metal electrocatalysts for the oxygen reduction reaction. ACS Appl. Mater. Interfaces 2009, 1, 1623-1639. [CrossRef] [PubMed]

36. Zhu, Y.; Zhang, B.; Liu, X.; Wang, D.W.; Su, D.S. Unravelling the structure of electrocatalytically active Fe-N complexes in carbon for the oxygen reduction reaction. Angew. Chem. Int. Ed. 2014, 53, 10673-10677. [CrossRef] [PubMed]

37. Cheng, T.; Yu, H.; Peng, F.; Wang, H.; Zhang, B.; Su, D. Identifying active sites of CoNC/CNT from pyrolysis of molecularly defined complexes for oxidative esterification and hydrogenation reactions. Catal. Sci. Technol. 2016, 6, 1007-1015. [CrossRef]

38. Liu, W.; Zhang, L.; Yan, W.; Liu, X.; Yang, X.; Miao, S.; Wang, W.; Wang, A.; Zhang, T. Single-atom dispersed Co-N-C catalyst: Structure identification and performance for hydrogenative coupling of nitroarenes. Chem. Sci. 2016, 7, 5758-5764. [CrossRef]

39. Chen, G.; Zhao, Y.; Fu, G.; Duchesne, P.N.; Gu, L.; Zheng, Y.; Weng, X.; Chen, M.; Zhang, P.; Pao, C.-W.; et al. Interfacial effects in iron-nickel hydroxide-platinum nanoparticles enhance catalytic oxidation. Science 2014, 344, 495-499. [CrossRef] [PubMed]

40. Li, X.; Ao, Z.; Liu, J.; Sun, H.; Rykov, A.I.; Wang, J. Topotactic transformation of metal-organic frameworks to graphene-encapsulated transition-metal nitrides as efficient fenton-like catalysts. ACS Nano 2016, 10, 11532-11540. [CrossRef] [PubMed]

41. Yao, Y.J.; Cai, Y.M.; Lu, F.; Wei, F.Y.; Wang, X.Y.; Wang, S.B. Magnetic recoverable $\mathrm{MnFe}_{2} \mathrm{O}_{4}$ and $\mathrm{MnFe}_{2} \mathrm{O}_{4}$-graphene hybrid as heterogeneous catalysts of peroxymonosulfate activation for efficient degradation of aqueous organic pollutants. J. Hazard. Mater. 2014, 270, 61-70. [CrossRef] [PubMed]

42. Duan, X.; Ao, Z.; Sun, H.; Indrawirawan, S.; Wang, Y.; Kang, J.; Liang, F.; Zhu, Z.H.; Wang, S. Nitrogen-doped graphene for generation and evolution of reactive radicals by metal-free catalysis. ACS Appl. Mater. Interfaces 2015, 7, 4169-4178. [CrossRef] [PubMed]

43. Wang, Y.; Sun, H.; Duan, X.; Ang, H.M.; Tadé, M.O.; Wang, S. A new magnetic nano zero-valent iron encapsulated in carbon spheres for oxidative degradation of phenol. Appl. Catal. B 2015, 172-173, 73-81. [CrossRef]

44. Sun, H.; Zhou, G.; Liu, S.; Ang, H.M.; Tade, M.O.; Wang, S. Nano-Fe(0) encapsulated in microcarbon spheres: Synthesis, characterization, and environmental applications. ACS Appl. Mater. Interfaces 2012, 4, 6235-6241. [CrossRef] [PubMed]

45. Du, Y.; Ma, W.; Liu, P.; Zou, B.; Ma, J. Magnetic $\mathrm{CoFe}_{2} \mathrm{O}_{4}$ nanoparticles supported on titanate nanotubes $\left(\mathrm{CoFe}_{2} \mathrm{O}_{4}\right.$-TNTs) as a novel heterogeneous catalyst for peroxymonosulfate activation and degradation of organic pollutants. J. Hazard. Mater. 2016, 308, 58-66. [CrossRef] [PubMed]

46. Feng, Y.; Wu, D.; Deng, Y.; Zhang, T.; Shih, K. Sulfate radical-mediated degradation of sulfadiazine by $\mathrm{CuFeO}_{2}$ rhombohedral crystal-catalyzed peroxymonosulfate: Synergistic effects and mechanisms. Environ. Sci. Technol. 2016, 50, 3119-3127. [CrossRef] [PubMed]

47. Cai, C.; Zhang, H.; Zhong, X.; Hou, L.W. Electrochemical enhanced heterogeneous activation of peroxydisulfate by Fe-Co/SBA-15 catalyst for the degradation of orange II in water. Water Res. 2014, 66, 473-485. [CrossRef] [PubMed] 
48. Deng, J.; Shao, Y.S.; Gao, N.Y.; Tan, C.Q.; Zhou, S.Q.; Hu, X.H. $\mathrm{CoFe}_{2} \mathrm{O}_{4}$ magnetic nanoparticles as a highly active heterogeneous catalyst of oxone for the degradation of diclofenac in water. J. Hazard. Mater. 2013, 262, 836-844. [CrossRef] [PubMed]

49. Wang, J.H.; Ozawa, K.; Takahashi, M.; Takeda, M.; Nonami, T. Photocatalytic properties and Sb-121 Mössbauer spectra of antimonic acid fine nanoparticles prepared by soft chemical solution process. Chem. Mater. 2006, 18, 2261-2264. [CrossRef]

50. Ozawa, K.; Wang, H.; Ye, J.; Sakka, Y.; Amano, M. Preparation and some electrical properties of yttrium-doped antimonic acids. Chem. Mater. 2003, 15, 928-934. [CrossRef]

51. Klencsár, Z. MossWinn Manual 2016. Available online: http://www.mosswinn.hu/downloads/mosswinn.pdf (accessed on 26 April 2017).

(c) 2017 by the authors. Licensee MDPI, Basel, Switzerland. This article is an open access article distributed under the terms and conditions of the Creative Commons Attribution (CC BY) license (http:/ / creativecommons.org/licenses/by/4.0/). 